\title{
Same Process, Different Outcomes: Group Performance in an Acquiring a Company Experiment ${ }^{*}$
}

\author{
Marco Casari $^{\mathrm{a}}$, Jingjing Zhang ${ }^{\mathrm{b}}$, and Christine Jackson ${ }^{\mathrm{c}}$ \\ ${ }^{a}$ Department of Economics, University of Bologna, \\ Piazza Scaravilli 2, 40126 Bologna, Italy \\ ${ }^{\mathrm{b}}$ Economics Discipline Group, University of Technology Sydney, \\ 14-28 Ultimo Road, Ultimo NSW 2007, Australia \\ ${ }^{\mathrm{c}}$ Krannert School of Management, Purdue University, \\ 403 W. State St., West Lafayette, IN 47906-2056, U.S.A.
}

\section{This version: July 15, 2015}

\begin{abstract}
It is still an open question when groups perform better than individuals in intellective tasks. We report that in an Acquiring a Company game, what prevailed when there was disagreement among group members was the median proposal and not the best proposal. This aggregation rule explains why groups underperformed with respect to a "truth wins" benchmark and why they performed better than individuals deciding in isolation in a simple version of the task but worse in the more difficult version. Implications are drawn on when to employ groups rather than individuals in decision making.
\end{abstract}

JEL Classifications: C91, C92, D03, D81

Keywords: winner’s curse, group decision making, communication, risky shift, herd behavior

Corresponding Authors: J. Zhang, Jingjing.Zhang@uts.edu.au, Phone: +61 295143064.

*Jingjing Zhang acknowledges financial support from the Swiss National Science Foundation (SNSF 135135) and the European Research Council (ERC Advanced Investigator Grant, ESEI-249433). We thank Anya Savikhin for valuable research assistance, Tim Cason for comments on an earlier version of the paper, two anonymous referees as well as seminar participants at the IMEBE meeting in Alicante, Spain, the ESA meetings in Tucson, and Bocconi University, Italy. 


\section{Introduction}

Many important economic, legal, political, and military decisions are made by groups. Can groups make better decisions than individuals in isolation? Since the last decade, researchers

have documented significant differences between individual and group decision-making in a large set of games in the experimental economics literature. ${ }^{1}$ For instance, Cooper and Kagel (2005) report that small groups in strategic tasks deliver outcomes beyond the most optimistic expectations i.e., better than those from the most skilled individual in the group. In contrast, other studies report no difference or even worse performance of groups relative to individuals (Davis, 1992; Kerr et al., 1996; Sutter et al., 2009). Yet until recently, economists paid little attention to when instead of whether groups perform differently than individuals.

The aim of this paper is to study under what conditions groups are superior and under what conditions are inferior to individuals in overcoming a well-known winner's curse problem. ${ }^{2}$ We will shed light on the possible explanations of the differences between individual and group decisions and deliver implications about when to employ groups rather than individuals in decision making.

To fulfill this aim, we compare individual and group performances in an Acquiring a Company experiment. The standard acquiring a company experiment is based on a bilateral bargaining game between a buyer and a seller who move sequentially (Samuelson, 1984; Samuelson and Bazerman, 1985). The buyer makes a take-it-or-leave-it offer to a seller who can either accept or reject. The interaction is non-trivial because the seller has more accurate information than the buyer about the value of the company. Although it has an objective solution, in experiments individuals hardly place optimal bids and many individuals actually acquire the company but incur losses; moreover they fail to correct their choices over time.

To reduce the complexity of the strategic interactions between sellers and buyers and the possible misunderstanding of the game, in our experiment, sellers were simulated by a computer

\footnotetext{
${ }^{1}$ For an excellent literature review comparing group and individual decision making, see Charness and Sutter (2012).

${ }^{2}$ The term "Winner's curse" refers to the irrational bidding behavior in common value auctions, consistently observed in the lab, where bidders often systemically overbid, resulting in an expected loss. Field evidence about overbidding has also been accumulated for a variety of similar economic situations, from mineral right auctions, eBay auctions, to baseball's free agency market, to IPOs pricing and to corporate takeovers (e.g., Bajari and Hortacsu, 2003).
} 
that accepted bids only when the bid was greater than or equal to the company's value. ${ }^{3}$ Having all subjects playing in the role of the buyer also eliminates any potential confounding effect due to other-regarding preferences. In this way, the strategic bargaining game is converted to a nonstrategic decision task while keeping the adverse selection problem unaffected. Relative to other games where optimal strategy depends on beliefs about players' rationality and strategic uncertainty, the behavioral data in this task may provide a sharper view of the decision making processes, especially when studying groups.

To the best of our knowledge, this is the first experiment investigating individual vs. group decision-making in an Acquiring a Company task. To provide implications on when groups outperform individuals, we vary the level of difficulty of the task: in the easy version, the majority of the individuals can solve the problem; while in the difficult version, only a minority can get the correct solution. Will groups place more optimal bids - or at least reduce the number of bids placed that loses money in expectation than individuals deciding in isolation in the easy task? If so, what is the mechanism that leads groups to perform better than individuals? Will groups still outperform individuals when the task is more difficult?

To investigate the forces that drive the different performance of groups and individuals, we break down the group decision making process into three steps: individual proposal step, a group chat step, and a decision making step. Using the bid proposals one can identify the precise aggregation rule that is used to reach consensus within each group: the group choice could follow the best proposal, the median proposal, the proposal of the majority, the worst proposal, a rotation scheme, or something else. We also control for possible shifts in risk preferences when moving from individuals to group decision making, which could partially account for individual vs. group differences.

Our analyses of groups of three members facing an Acquiring a Company task generate several important results. We report that in the easy task, groups substantially reduced the winner's curse and generally placed better bids than individuals deciding in isolation. Groups did however underperform with respect to a "truth wins" benchmark, although they outperformed individuals deciding in isolation. This result was attributed mainly to the aggregation rule of individual proposals within the group. When there was disagreement within a group - what

\footnotetext{
${ }^{3}$ All studies reviewed from the literature used robot sellers, and so do we, with the exception of Carroll et al. (1990, treatments 5 and 6 only) and Cooper and Sutter (2011).
} 
prevailed was not the best proposal, i.e. the so called "truth wins norm," but the median proposal, which is more typical for tasks without an objective solution. This median-aggregation rule can also explain the observed inferior performance of groups relative to those of individuals when they face the difficult task. When the task is sufficiently simple for most people, groups can provide better solutions than individuals acting in isolation because those with the wrong answer are almost always a minority. When the task is difficult, we shall be more cautious to use groups as the decision making unit. Thus the present paper identifies some conditions under which the same basic processes of group decision making can lead to good performance in certain contexts and poor outcomes in other contexts. ${ }^{4}$

The paper opens with a literature review in section 2, and presents the experimental design in section 3 . The results are split into the main ones in sections 4 and the others in section 5. The paper closes with discussion and conclusions in section 6.

\section{Literature Review}

We reviewed nine available experimental studies that have utilized the Acquiring a Company task in the economics and management literature. ${ }^{5}$ In none of them, do naïve behavior and the winner's curse disappear with a reasonable amount of experience and feedback. Indeed, individuals in these studies failed to avoid naïve bidding and the winner's curse even when they were paid for good performance, when their intellective reputations were at stake, when they were given hints, and when participants were unusually analytical. In all of these studies, decision makers were individuals, with the exception of Cooper and Sutter (2011) where, teams of two players, one as a buyer and the other as a seller played a series of the acquiring a company game against sellers and buyers from different teams and shared earnings equally. Their goal is to examine the impact on performance of endogenous versus random role assignment within

\footnotetext{
${ }^{4}$ This complements to previous social psychology literature arguing that different performance outcomes are a function of inherently different processes (Brodbeck et al. 2007; De Dreu et al. 2008). Brodbeck et al. (2007) propose a theoretical model that explains how the interaction between asymmetries in information distribution prior to group decision making and asymmetries in information processing during group decision making affects group performance. De Dreu et al. (2008) theorize that group performance is a function of social motivation, epistemic motivation and their interaction. When decision urgency is low, group outcome benefits from prosocial motivation coupled with high levels of epistemic motivation. When groups face emergency situations, groups perform better when prosocial motivation is paired with low levels of epistemic motivation.

${ }^{5}$ Ball, Bazerman, Carroll (1991), Charness and Levin (2009), Cooper and Sutter (2011), Holt and Sherman (1994), Selten, Abbink, and Cox (2005), Bereby-Meyer and Grosskopf (2008), Grosskopf, Bereby-Meyer, Bazerman (2007), Carroll, Delquie, Halpern, Bazerman (1990), Tor and Bazerman (2003). A design comparison is provided in Appendix, Table A1.
} 
teams whereas in this study all team members were buyers and the main focus is to see when group decisions are more rational than individual ones.

Our Acquiring a Company task is closer to an intellective task than it is to a judgmental task. It is also easily demonstrable because it is straightforward to explain to others once a subject understands what the optimal bid is. ${ }^{6}$ In comparing individual and group performance on an intellective task, Lorge and Solomon (1955) proposed to replace absolute performance of the group with the "truth wins" benchmark (i.e., the group should be able to achieve a correct answer if at least one member would have chosen it in isolation). Thus, if a fraction $\mathrm{p}$ of individuals working alone reaches the correct solution, the probability that in a randomly selected group of $\mathrm{n}$ persons at least one knows it is $1-(1-p)^{n}$. The truth wins benchmark sets a higher standard for the group superiority than absolute performance.

Research on group performance in the psychology literature documents that freely interacting groups very rarely exceed and usually fall below the truth wins standard (Davis, 1992, Kerr et al., 1996), however, more recent research conducted by Laughlin and colleagues suggest that in terms of intellective tasks, the absolute performance of groups is superior to the performance of individuals (Laughlin, et al., 2002; Laughlin, et al., 2003; Laughlin, et al., 2006). Specifically, in a series of experiments conducted by Laughlin and colleagues, three, four, and five-person problem-solving groups performed better than the best of an equivalent number of individuals on a difficult intellective task (e.g., letters-to-numbers problems). The superior performance of groups over individuals was attributed to the demonstrability of the task. Laughlin and Ellis (1986) proposed four conditions of demonstrability, which includes group consensus on a verbal or mathematical conceptual system, sufficient information for a solution, sufficient knowledge of the system to recognize and accept a correct solution if it is proposed, and correct members must have sufficient ability, motivation, and time to demonstrate the correct solution to the incorrect members. For intellective tasks, groups perform increasingly better than individuals as the demonstrability of the tasks increases, such that groups perform at the level of the average individual for weakly demonstrable tasks and perform at the level of the

\footnotetext{
${ }^{6}$ The psychological literature on group versus individual decision-making distinguishes between judgmental and intellective tasks (Laughlin, 1980). A judgmental task involves problems where there is no obvious "correct" action and individuals may legitimately differ on their choices because of their values or preferences. In contrast, an intellective task has a "correct" solution; sometimes this solution is difficult to discover and sometimes it is easy to discover and demonstrate to others.
} 
best individual for highly demonstrable tasks (Laughlin and Ellis, 1986). Indeed, groups have been shown to perform comparably to the best of an equivalent number of independent individuals on intellective tasks when they were given sufficient information and time (Laughlin, et al., 1991).

How groups combine individual preferences is also determined in part by the demonstrability of the task. Laughlin (1999) postulated that groups chose to resolve disagreement among individual preferences using various social combination models including voting (majority or plurality), turn taking (i.e., proportionality), and demonstration (i.e., truthwins and truth-supported wins), among others. In a review of the group's performance and decision-making literature, Kerr and Tindale (2004) concluded that groups rarely combined their individual preferences in an optimal way; however, groups can maximize their performance through the use of simply majority processes. The review also concluded that majority and median models, which allow groups to give more weight to those members whose preferences are similar, were found to best represent the consensus processes utilized by groups in combining member preferences.

Experimental economics on group performance in intellective tasks focus more on the effect of learning and provide mixed results. In a beauty-contest game, Kocher and Sutter (2005) found that groups of three subjects did not do more iterations of reasoning than individuals, but learned faster than individuals via face to face communication. In signalling games, Cooper and Kagel $(2005,2009)$ reported that teams of two played more strategically than individuals after exchanging messages in online chat rooms and a change in the meaningful context of the game stalled individual learning process but had no effect on the strategic play of teams. They conclude that teams outperformed the truth win benchmark using a simulation of team play based on randomly drawing two individuals from the individual treatment. Instead of relying on simulated data, our within-subject design allows us to count the instances in which the optimal proposal from the individual member prevailed to a final group choice. Also, we examined team play in groups of three rather than two, which permits interesting majority or minority behaviour. In auctions, two experimental studies employed groups as bidders. Cox and Hayne (2006) compared the performance of individuals and groups of five members in a sealed-bid common value auction. Groups performed better when the information was common to all group members rather than when there was a need of information sharing within the group. In the former case, 
individuals deciding within groups earned more than when deciding in isolation. In the latter case, earnings were roughly equivalent. Our design resembles the treatment with common information among all group members; hence it relieves groups from the additional burden of information sharing. Sutter et al. (2009) compared the performance of individuals and groups of three members in an English auction with a private and a common value component. They reported that groups submitted more winner's curse bids and therefore earned lower profits than individual bidders. They attributed this findings to individual-group differences toward competition, i.e., groups competing with other groups are more aggressive than individuals competing with other individuals, which is absent in our design as there is just one buyer and the seller is a robot. Moreover, bidders can more easily explain to others the rationale for an optimal bid in our Acquiring a Company task than in a common value auction. One reason is that the optimal strategy does not depend on the bids of others. In Section 6 we will come back to the above studies and interpret the results in light of our findings.

\section{Experimental Design}

There were two treatments with an "easy" Acquiring a Company task and two treatments with a "difficult" task. In every session 15 subjects faced several repetitions of the task. Within a session there were a Control and Main part. In the six initial repetitions, or periods, of the Acquiring a Company task, all subjects decided in isolation ("Control part"), while in the following twenty periods, the decision making processes varied across treatments ("Main part”). In the main part, decision making of subjects continued to be done in isolation in the Individual treatment, while subjects had to reach a consensual decision within their group in the Group treatment.

In our experiment, all subjects faced the Acquiring a Company task always as potential buyers. The buyer made a take-it-or-leave-it offer $b$ (an integer between 0 and 360) to a seller

whose company's value was $s$. Sellers were simulated through robots who accepted bids only when the bid $b$ was greater than or equal to $s$. The instructions explained how robot sellers made their choices. The payoffs for a buyer was 0 if the seller rejected and $(1.5 s-b)$ if she accepted. The buyer only knew that each realization of $s$ had equal probability. The difficulty of the task depends on how many values the company could take. In the literature the range is between two and infinite possible company values. For the task with infinite possible values, past experiments 
have shown that the share of sub-optimal bids is very high, suggesting that a level of difficulty beyond the abilities of most participants (e.g., Bereby-Meyer and Grosskopf, 2008). Charness and Levin (2009) compared simple designs with a discrete set of possible company values either 2, 4, or 100 values - and reported that subjects had more difficulty handling the 100 value than the 2 or 4 value tasks.

In our easy task the company could take on only five possible values, $s=38,60,90,130$, or 240. These values were not evenly spaced for two reasons. First, it avoids placing the equilibrium bid at a corner of the choice space, where the most profitable activity is either to bid zero and never acquire the company or to bid the highest value and always acquire it. Such designs have advantages but can induce boredom. Placing the equilibrium bid away from the corners of the actions space is also likely to facilitate the convergence of groups with heterogeneous views on the correct solutions; the equilibrium bid was not in the middle of the action space, either. Second, to have distinct predictions for naive and rational bidders, while distancing the latter prediction from the middle of the action space, where there oftentimes are many confused subjects who would otherwise be mistaken for rational players (Holt and Sherman, 1994, Selten et al., 2005). In the difficult task the company could take on one hundred possible values, $\mathrm{s}=21,22, \ldots, 120$. As mentioned, the values were not $0, \ldots, 100$ in order to avoid corner solutions. $^{7}$

To sum up, the task was a decision problem with imperfect information. The informational obstacle of the buyer was offset by an assumption that the buyer's value was 1.5 times the seller value, $s$. The optimal and naïve bidding strategies in this task were first modeled by Holt and Sherman (1994) in an environment with continuous strategy space where company values for the seller were uniformly distributed between $X$ and $X+R$. In Holt and Sherman (1994) the expected gain to a buyer equals to the value of the company less the amount bid for it, weighted by the probability of having one's bid accepted. Such weight can be represented by the factor $(b-X) / R$, which shows the probability that $s$ is less than $b$. The optimal bidding strategy will necessarily consider that the seller accepts only if the company value is lower than $b$ (or equal). Hence, it adjusts for the additional information that will be unveiled in the event of a deal. In the event that the seller

\footnotetext{
${ }^{7}$ To make the decisional process more comparable across treatments, all treatments followed the same random draw procedure in the "main" part. That is, every period the computer independently drew at random one company values for each group of three persons. In the individual treatment, even though there was no group decision making in the main part, the same company value was given to each members of the groups.
} 
accepts a bid $b$, the buyer can conjecture that the expected value for the seller will be in-between $X$ and $b$, and more exactly $X+(b-X) / 2$. For a rational bidder who is risk neutral, the optimal decision is to maximize the rational objective function below, which is the product of the acceptance probability times the expected payoffs conditional on acceptance:

$$
\begin{gathered}
\left(\frac{b-X}{R}\right) \cdot\left[1.5\left(X+\frac{b-X}{2}\right)-b\right] \text { (rational objective) } \\
\left(\frac{b-X}{R}\right) \cdot\left[1.5\left(X+\frac{R}{2}\right)-b\right] \text { (naïve objective) }
\end{gathered}
$$

In contrast, a naive bidder is defined as someone who neglects the information conveyed by winning and assumes that the value of the company for him/her is $1.5(X+R / 2)$, where $X+R / 2$ is the expected value of $s$. This generates the naive objective illustrated above. Building upon these arguments, Holt and Sherman (1994) derived the rational and naive bids as follow:

$$
b_{\text {rational }}=2 X \quad b_{\text {naive }}=\frac{5}{4} X+\frac{1}{4} R
$$

The predictions within the experimental treatment follow from this framework by considering a discrete strategy space. In the 5-value task, a bid of 60 is the risk-neutral Nash equilibrium (RNNE) strategy for the buyer and yields an expected profit of 5.4. Table 1 shows buyer's profits for the RNNE strategy and other bidding strategies. Instead, an incorrect reasoning may lead some participants to bid 90 and earn an expected profit of 2.4, which is suboptimal. We computed this prediction following the model of naïve bidding in order to select a design for the experiment with a rational bid lower than the naïve bid. A naïve bidder does not condition the value of the company on the level of the accepted bid, rather, assumes that the value is always the expected value of $s$, which is 111.6. A naïve bidder erroneously thinks a bid of 90 would yield an expected profit of $0.6 \times(1.5 \times 111.6-90)=46.44$. Instead, when placing a bid of 90, the company is sold only for values 38, 60, 90 but not for 130 and 240. For a rational bidder, the expected value conditional on being accepted is not 111.6, but $(38+60+90) / 3=62.66$. Thus, the expected profit is 2.4 (Table 1). When the buyer does not take into account that acceptance is itself an informative event, the buyer may overbid and even incur an expected loss. For the adopted parameters, optimal bidding (RNNE) yields a $40 \%$ probability of acquiring the 
company, which ensures that the participants stayed engaged in the task. ${ }^{8}$ Similarly, in the 100value task, the RNNE bid is 42 and the naïve bid is 63.75. Any bid above 63 generates an expected loss.

To favor learning, each participant observed the company value at the end of each period - even when the company was not acquired. There was a practice period with forced input. In all treatments, the initial six periods involved individual decision making and every period the computer randomly drew 15 company values, one for each participant (control part).

The rules in the following twenty periods differed by treatment (main part). In the Individual treatment, the Acquiring a Company task continued to be individual decision making except that while submitting a bid, subjects also stated their confidence level in the bid (low, medium, high) without monetary incentives and could add a brief text with reasons for the choice of that bid, which only the experimenter could observe.

In the Group treatment, participants faced the Acquiring a Company task in groups of three members, which were randomly formed at the beginning of the session and held fixed through the session. Every period included a proposal step, a chat step, and a bidding step. In the proposal step, subjects submitted an individual bid proposal, a confidence level in their proposal (low, medium, or high) without monetary incentives, and could also send a brief text explaining the proposed bid. ${ }^{9}$ This information was placed on a public board for all three group members to see. Participants then had two minutes to send free-form messages to others in their groups. ${ }^{10}$ Messages were recorded. In the bidding step, subjects had up to three rounds to reach a consensus on their group bid without further possibility to chat. If there still was no unanimity, no group bid was submitted and group members earned zero profits for that period. Under a unanimity rule, subjects have strong incentives to listen to the reasons of every group member with a different opinion; subjects have also incentives for communicating clearly and convincingly one's position to others in order to influence group decisions.

Before the Acquiring a Company task, participants faced lottery tasks along the lines of

\footnotetext{
${ }^{8}$ Having 240 as the highest possible company value generates an adequate "profit distance" of $7.5 \%$ between the RNNE bid of 60 and the naïve bid of 90. Consider that, after fixing the lower four company values, a highest possible company value of 183 generates equal profits for the 60 and the 90 bids.

${ }^{9}$ Confidence levels are part of the cheap talk among group members. Incentivizing them would have likely biased the main bidding choice, which was the target of the experiment, and added complexity to the design.

${ }^{10}$ In the chat window, participants received an id number 1-3 in the order they sent messages in that specific period. We asked participants to follow two basic rules: to be civil to one another and not use profanities, and not to identify themselves in any manner.
} 
Holt and Laury (2002) to measure risk attitude. A first part elicited individual risk attitude and a second part elicited group risk attitude. Each part comprised fifteen binary decisions between a "safe" and a "risky" option. The safe option involved a deterministic earning (50 tokens) and the risky option was a lottery with either a 150 earning or 0 (see Table A3 in Appendix). The percapita expected payoffs were equal in the two tasks. Only one decision from the individual lottery part and one from the group lottery part was randomly selected for payment at the end of the session. Group members had to submit unanimous choices after chatting. ${ }^{11}$ The group composition was the same here and in the Acquiring the Company task. Zhang and Casari (2012) fully illustrated the design and results. The elicitation of risk attitudes both at the individual and at the group level was instrumental in interpreting the choices in the Acquiring a Company task.

Participants started with a 200 token endowment in the control part and a 300 token endowment in the main part of the easy task. In the difficult task, we increase the endowment to 250 and 400 respectively to account for the lower expected profit relative to the easy task. In equilibrium, the individual period earnings were identical between individual and group treatments in a given task. Subjects were paid for all periods. ${ }^{12} 30$ subjects participated in the Individual treatment and 60 in the Group treatment of the easy task and 15 in the Individual treatment and 30 in the Group treatment of the difficult task (Table 2). Participants were randomly recruited from the undergraduate campus population of Purdue University and nobody participated in more than one session. Instructions were read aloud and subjects received a written copy. Sessions were run on a z-tree application (Fischbacher, 2007) and lasted on average about two hours. A subject earned on average about \$20 in the easy task and \$25 in the difficult task, with a guaranteed minimum payment of $\$ 5$. We paid $\$ 0.03$ for each experimental token.

\footnotetext{
${ }^{11}$ There were a proposal phase, a chat phase, and a group choice phase. Everyone simultaneously made an individual proposal about each of the fifteen lottery choices. Participants could then chat with their group. Any line with disagreement was highlighted. If the choices of all three group members were identical for a specific decision line, then we had a group choice. If case of disagreement, there were two other rounds of interaction. In case the group was still in disagreement in the line selected for payment, then earnings were zero for that part.

${ }_{12}$ Note that when cumulative earnings were low, there was a problem of limited liability, which we will discuss in the Result section. The instruction explained: "What if my earnings are negative? They will be compensated with your other gains. More precisely, if you have a loss in a single period, it will decrease your cumulative earnings. If your cumulative earnings in this part are negative, they will decrease your earnings in other parts of the experiment. However, if at the end of the session your earnings are negative, you will receive $\$ 5$.”
} 


\section{Main Results}

There are four main results from the Acquiring a Company experiment. Two measures of performance are considered: the fraction of optimal bids and the fraction of winner's curse bids, e.g. those that yielded an expected loss. We single out winner's curse bids from other suboptimal choices because they entail particularly severe departures from optimal bidding: in expectation a subject is better off bidding 0 - or not bidding at all by vetoing the group decision - rather than placing a winner's curse bid.

Result 1: In the individual treatment, there was no significant improvement in performance over time from the control part to the end of the main part in terms of fractions of optimal or winner's curse bids. This result holds both for the easy and difficult tasks.

We first present evidence supporting Result 1 for the easy task. Recall subjects could bid any integer value between 0 and 360. In the easy task, we consider (near) optimal bids those of 60 or 61, in case subjects did not understand the tie-breaking rule, and winner's curse bids those integers in the intervals [58, 59], [74, 89] or [95, 360]. Table 3 and Figure 1 report the descriptive statistics. Overall, in the individual treatment only a minority of bids were optimal: the initial fraction was $35.6 \%$ (control part) and it remained about constant, reaching $35.4 \%$ at the end of the main part (periods 13-20). This difference was non-significant according to a Wilcoxon signed-rank test $(\mathrm{N}=30, \mathrm{p}=0.992) .{ }^{13}$ The fraction of winner's curse bids was at an initial level of $20.0 \%$ and remained about constant at $19.2 \%$. Also this difference was nonsignificant according to Wilcoxon signed-rank tests $(\mathrm{N}=30, \mathrm{p}=0.339)$.

In some cases overbidding may be rational because of limited liability issues. For instance a subject with a low cash balance can expect to earn more by bidding 240 instead of the equilibrium bid of 60 in the easy task or by bidding 120 instead of 42 in the difficult task. ${ }^{14}$ In the data, these occurrences involved only $1.5 \%$ of all bids in the easy task and none of the bids in

\footnotetext{
${ }^{13}$ All reported p-values are based on two-sided tests unless otherwise stated.

${ }^{14}$ In the easy task (difficult task), bidding 240 (120) yields a positive profit with probability $0.2(0.4)$ and a loss y with probability $0.8(0.6)$. If the cash balance is below $y=23.25(y=57.8)$ the eventual loss is inconsequential. When $\mathrm{y}<23.25(\mathrm{y}<57.8)$ the expected profit from a $240(120)$ bid are higher than 5.4 (1.1) i.e. the expected profits from an optimal bid. Two caveats are in order. First, we guaranteed a \$5 minimum earnings, which translates into 166.6 tokens, hence the relevant threshold for cash balances is 189.9 (224.4). Second, the reference cash balance includes the expected earnings from the individual lottery part and 2 lotteries, the part 3 and 4 endowments and the cumulative profits from the company takeover game up to that period.
} 
the difficult task. Hence, keeping those observations affected by limited liability issues does not affect the main results. ${ }^{15}$

In the difficult task, we consider (near) optimal bids those in the range [31, 53] while winner's curse bids those in the range $[64,360] .{ }^{16}$ Overall, in the individual treatment for the difficult task the fraction of optimal bids was $15.6 \%$ in the control part and $22.5 \%$ in the end of the main part. This difference was non-significant (Wilcoxon signed-rank test, $\mathrm{N}=15, \mathrm{p}=0.234$ ). The fraction of winner's curse bids remained about constant, from $70.0 \%$ in the control part to $68.3 \%$ in the end of the main part. This difference was non-significant according to Wilcoxon signed-rank tests $(\mathrm{N}=15, \mathrm{p}=0.455)$.

Result 2: In the easy task, by the end of the main part groups performed significantly better over time from the control part in terms of the fraction of optimal and winner's curse bids. The significant improvement took place in the transition to group decision-making and not from experience.

Result 3: In the difficult task, by the end of the main part there were no significant improvements of groups with respect to the control part in terms of the fraction of optimal and winner's curse bids. In the transition to group decision-making, group performance became significantly worse than in the control part, and then significantly improved with experience.

Table 3 and Figure 1 provide support for Results 2 and 3. In the easy task of the group treatment, the fraction of optimal bids increased from an initial level of $30.6 \%$ (control part) to $51.9 \%$ in the end of the main part (periods 13-20). In addition, the fraction of winner's curse bids declined from an initial level of $18.3 \%$ to $10.6 \%$. These differences were both significant according to Wilcoxon signed-rank tests ( $\mathrm{N}=20, \mathrm{p}=0.038$ and $\mathrm{N}=20, \mathrm{p}=0.026$, respectively). The improvement took place in periods 1-6 of the main part during the transition from individual to group decision-

\footnotetext{
15 Table 3 includes those observations. We dropped them instead from all following statistical and regression analyses.

${ }^{16}$ In the difficult task, the optimal bid is 42 . The range of near optimal bids covers $22 \%$ of the action space to include also approximately optimal bids and to facilitate the statistical comparison with the easy task, where the optimal bid is linked to one of the five company value (20\% chance in case of random uniform choice). The expected profit from a bid of 31 is the same as from a bid of 53. In both easy and difficult tasks, near optimal bids are never loss-free.
} 
making ( $\mathrm{N}=20, \mathrm{p}=0.108$ for optimal bids and $\mathrm{N}=20, \mathrm{p}=0.035$ for winner's curse bids, respectively). No difference is observed when we compare the first 6 periods to the end of the main part $(\mathrm{N}=20, \mathrm{p}=0.376$ for optimal bids and $\mathrm{N}=20, \mathrm{p}=0.932$ for winner's curse bids, respectively). Hence, it was the effect of group membership more than group learning (Figure 1).

Instead, in the difficult task of the group treatment, the fraction of optimal bids at the initial level of $22.2 \%$ (control part) were not significantly different from the $17.5 \%$ at the end of the main part (periods 13-20) according to a Wilcoxon signed-rank test $(\mathrm{N}=20, \mathrm{p}=0.259)$. The fraction of winner's curse bids declined from $64.4 \%$ to $48.8 \%$ but this difference was nonsignificant according to Wilcoxon signed-rank test $(\mathrm{N}=10, \mathrm{p}=0.202)$. This overall picture of non-significant change hides two opposite shifts (Figure 1). First, the transition from individual to group decision-making that caused a worsening of performance, with optimal bids at $6.7 \%$ and winner's curse bids at $75 \%$ in periods 1-6 of the main part (only the former is significantly different between control part and the first 6 periods of main part, $N=10, p=0.040$ ). Second, group learning caused a significant improvement of performance (comparing periods 1-6 to periods 13 -20 of the main part: $\mathrm{N}=10, \mathrm{p}=0.084$ for optimal bids and $\mathrm{N}=10, \mathrm{p}=0.011$ for winner's curse bids, respectively).

Another way to assess performance is to trace groups over time. In the easy task, most groups exhibited an improvement in bid quality over time (Figures 2a and 2b). One can measure the improvement by comparing the average quality bid score in the earlier periods $(1,2,3)$ versus the later periods $(17,18,19)$. We did not include the last period to avoid catching end-ofgame effects and considered three-period intervals to account for rotating strategies among group members. When average scores did not change, the tie-breaking rule was the average quality score of the proposed bids in the earlier vs. later periods. We report that 14 groups exhibited an improvement (70\%), 1 group stayed constant, and 5 groups got worse. In the individual treatment, the improvement over time in the main part was less frequent. We report that 12 individuals exhibited an improvement (40\%), 7 individuals stayed constant, and 11 individuals got worse. This difference is significant according to a Fisher's exact test on the percentage of improved groups and individuals ( $\mathrm{p}=0.048$ ). Also in the difficult task there was an improvement, although smaller. We report that 6 groups exhibited an improvement (60\%), 3 group stayed constant, and 1 group got worse. In the individual treatment, the improvement over time in the 
main part was less frequent. We report that 7 individuals exhibited an improvement (46.7\%), 1 individual stayed constant, and 7 individuals got worse. This difference is not significant on the percentage of improved groups and individuals (Fisher's exact test, $\mathrm{p}=0.688$ ).

Result 4: Over time the fraction of optimal bids followed opposite trajectories in the easy vs. the difficult task. The change from the control part to the end of the main part significantly favoured the group treatment over the individual treatment in the easy task. The opposite was true for the difficult task.

Support for Result 4 is in Table 3. In the easy task the fraction of optimal bids increased and the fraction of winner's curse bids decreased from the control to the main part in both treatments. The absolute magnitude of these improvements, though, was larger in the group treatment than in the individual treatment: +19.9 vs. +1.9 for optimal bids and -8.5 vs. -1.9 for winner's curse bids. These differences across treatments are marginally significant for the fraction of optimal bids (Robust Rank Order tests: $n=30, m=20$, one-tailed asymptotic $p=0.057$ ), and for the fraction of winner's curse bids (Robust Rank Order tests: $n=30, m=20$, one-tailed asymptotic $p=0.057$ ). The pattern was rather different in the difficult task. The direction and magnitude of the improvements in the difficult task actually disfavored the group treatment over the individual treatment: -9.2 vs. +7.1 for optimal bids and -3.9 vs. -4.3 for winner's curse bids. These differences across treatments are statistically significant for the fraction of optimal bids (Robust Rank Order tests: $\mathrm{n}=15, \mathrm{~m}=10, \mathrm{p}=0.006) .{ }^{17}$ The poor group outcome in terms of optimal bidding in the difficult task is in line with the results of previous studies on group bidding in auctions, where group decision making did not substantially improve performance (Cox and Hayne, 2006, Sutter et al., 2009). In Section 6 we provide a unified interpretation for this and other results.

\section{Additional Results}

Why and when do groups outperform individuals? This section discusses interpretations and

\footnotetext{
${ }^{17}$ In the control part, there are no significant differences in the fraction of optimal bids and fraction of winner's curse bids across individual and group treatments for both the easy and difficult tasks (Robust Rank Order tests: $\mathrm{n}=30, \mathrm{~m}=60, \mathrm{p}=0.189$ for optimal bids and $\mathrm{p}=0.426$ for winner's curse bids in the easy task. In the difficult task, $n=15, m=30, p=0.246$ for optimal bids and $p=0.369$ for winner's curse bids). Thus clearly the superiority of groups is not due to a better cohort of participants.
} 
qualifications for the main findings in the form of four additional results. Results 5 and 6 open the section by presenting evidence on how individual bid proposals are combined into a final group bid in the main part.

Result 5: Groups underperformed with respect to a "truth wins" benchmark.

In intellective tasks, such as the Acquiring a Company task, one smart person who knows the optimal bidding strategy can explain it to the other two group members and hence prove to them the superiority of his or her proposal. ${ }^{18}$ In a well-working group, this may well happen but it actually did not in the experiment. Consider the following back-of-the-envelope calculations. In the easy task, about $30.6 \%$ of control part bids were optimal. Absent any learning, the chances that at least one group member proposed the optimal strategy were $66.4 \%$, which contrasts with the considerably lower level of $50.5 \%$ in the main part (Table 3$)^{19}$. In the difficult task, about $22.2 \%$ of control part bids were optimal, which amount to a predicted optimal strategy of $52.9 \%$ to be compared with the actual $13.0 \%$ level. ${ }^{20}$ Hence, the group does not meet the truth-wins norm, which is also in line with Charness et al. (2010)'s finding about conjunction fallacy reasoning.

A key design feature of the Group treatment was the posting of individual bid proposals before starting the group discussion; hence there is a complete record of ex-ante agreement or disagreement among group members. There was lively disagreement within groups: overall exante disagreement is present in about $53.8 \%$ of cases of the easy task and $61.0 \%$ of cases in the difficult task. We label as disagreement a case where at least one member's initial bid proposal was different from the final group bid. Ex-ante disagreement reduced over time from $66.7 \%$ (periods 1-6) to $45.6 \%$ (period $13-20$ ) in the easy task and from $68.3 \%$ to $55 \%$ in the difficult task. At the end of each period, though, all groups eventually reached a unanimous decision. A group-by-group analysis focused on winner's curse bids confirms the underperformance of groups with respect to a truth wins norm when dealing with an Acquiring a Company task (Table 4).

\footnotetext{
${ }^{18}$ At the beginning of each period, subjects must make a proposal in the pre-discussion stage which worked as an open brick for their discussion and also saved their chat time which was up to 2 minutes. There were 15 periods involved. Thus the smart subject had 30 minutes in total to explain the strategy to the other two.

${ }^{19}$ The difference is significant at $10 \%$ (Wilcoxon signed-rank test, $n=20$, $p$-value $=0.09$, one sample t-test $p$-value $=0.08$ ).

20 The difference is significant at $1 \%$ (Wilcoxon signed-rank test, $\mathrm{n}=10, \mathrm{p}$-value $=0.007$, one sample $\mathrm{t}$-test $\mathrm{p}$ value $=0.002$ ).
} 
In the Group treatment, individual proposals are not incentivized. Hence, they may be cheap talk employed to influence group decision making in case of disagreement. In the initial periods it is more likely that proposals would be truthful as a subject does not know how others would approach the task. In later periods, subjects knew that often time the median proposal or close to median proposal prevailed. Thus if a subject preferred bid is the median among her group members, there is no incentive to change it. In case it is different from the median, it will most likely not be chosen; hence the subject could inflate it in the attempt to pull the group decision more in the direction of his preferred bid. From the experimental data, it is unclear how relevant this phenomenon could have been and how effective it may have been. For the purpose of our analysis it has only a minor impact as we consider the ranking of bids and not their absolute magnitude.

Result 6: If there was disagreement among group members, in most cases the group bid coincided with the median proposal, both in the easy and difficult tasks.

In the easy task, the final group bid was the median proposal, or closest to the median, in $76.7 \%$ of the cases; it was better in $6.5 \%$ of the cases and worse in $16.7 \%$ of the cases. In the difficult task the pattern was similar, as the final group bid was the median proposal, or closest to the median, in $68.0 \%$ of the cases; it was better in $14.8 \%$ of the cases and worse in $17.2 \%$ of the cases. ${ }^{21}$ Hence, the evidence points toward a median aggregation rule for group decisions. As we will discuss below, a median aggregation rule could explain both the positive performance of groups in the easy task and their poor performance in the difficult task. In order to understand how the group dynamic aggregated diverging opinions, here we study exclusively situations of disagreement. Probit regressions study the subsample of groups in disagreement in two distinct specifications (marginal effects are reported in Table 5). The dependent variable was 1 when an individual proposal became a group choice, 0 otherwise. Regressors included whether the proposal was a median as well as common to the majority, whether it was a median but not common to the majority, and whether it was the proposal in the group that yielded the highest

\footnotetext{
${ }^{21}$ Some group bids were different from all the individual proposals of group members (3\% in the easy task and 28\% in the difficult task). The classification in the main text assigned those cases according to the closest distance in terms of expected profit between the group bids and each of the individual proposals. The regressions in Table 4, instead, coded as "median" only those proposals that were identical to the group bid.
} 
expected payoff. Demographic regressors included risk attitude, confidence level, college major, and gender. Period dummies were also included but not reported in the table.

Some regressions pool data from periods 1-6 and others pool data from periods 7-20. The comparison between the regressions using the first 6 and the last 14 periods allowed us to examine the change in the determinants of group outcome across time. The main result from the first specification is that the median proposal was the strongest determinant of group choice, especially when it was common to a majority. Such strong impact remains over time. In the second specification, it emerges that the best proposal was no more likely to be chosen in group choices, which suggests that the "truth wins" norm (Lorge and Solomon, 1955) does not apply to this experiment. Risk preferences of the proponent had unclear effects on the proponent's impact on group choices while male participants were significantly more likely to influence the group choices in one specification of the difficult task. High confidence and major did not seem to be important factors.

One aspect that needs clarification is how group decisions strictly based on the median bid proposal could still improve performance in the Acquiring a Company task. We ran period by period simulations by taking the median bid among three random bids drawn from the pool of individual bids that subjects placed in that period in a given part in the individual treatment. For the group treatment, we used individual bids in the simulation for the control part and individual proposals for the main part. We consider averages of 6000 simulations for each period. When comparing the actual results from Table 4 to the simulation results, one can see that a mechanical aggregation of the individual bids into a group choice using the median rule improves bidding in the easy task, in particular it should lead to a reduction of about half of the frequency of winner's curse bids, from $18.3 \%$ to $9.4 \%$ (See Table A2, simulations on the main part of the Individual treatment $)^{22}$. This reduction is similar to what one observes in the experimental data for the main part of the Group treatment (9.8\%, Table 3). While encouraging, the result that groups outperform individuals does not extend to the difficult task where a majority of bids are winner's curse bids. In the difficult task, the mechanical median aggregation rule results in a decrease of the fraction of optimal bids from the observed $22.7 \%$ (individual treatment main part) to 16.76\%,

\footnotetext{
${ }^{22}$ The difference is significant at $10 \%$ according to the Wilcoxon signed-rank test, $n=30$, $p$-value $=0.07$ and $5 \%$ according to one sample t-test $\mathrm{p}$-value $=0.02$.
} 
a level similar to the observed data in the group treatment (13\%). ${ }^{23}$

Hence, a median aggregation rule in group decision can explain the better performance of groups compared to individuals with respect to placing winner's curse bids in the easy task and worse performance in the difficult task.

Result 7: Participants employed the veto power less often than optimal.

The design set strong incentives for subjects to communicate and negotiate within the group because every group member had veto power on the final bid. If there was disagreement on the group choice, the group lost the opportunity to place a bid for the period and everyone in the group earned zero. ${ }^{24}$ The veto power could have been usefully employed by a subject every time others in the group wanted to place a winner's curse bid. For risk neutral and risk averse participants, a sure gain of zero is preferred to an expected loss. Did participants employ such veto power? They did less often than what would have been necessary to avoid all expected losses. First, there was no case where groups did not reach a final bid by the third trial. Second, the aggregation of winner's curse proposals did not differ from the aggregation of proposals in general (Table 4). Our conjecture is that Result 7 is due to pressure to conform in group decision making. In the easy task, when the proposal of one member was a winner's curse bid and the other two were not, it prevailed in $25.0 \%$ of the cases. When the proposals of two members were winner's curse bids and the other was not, it prevailed in $77.8 \%$ of the cases. In the difficult task, when the proposal of one member was a winner's curse bid and the other two were not, it prevailed in $30.4 \%$ of the cases. When the proposals of two members were winner's curse bids and the other was not, it prevailed in $75.0 \%$ of the cases. These percentages are in line with those stated in Result 6. In the hypothetical case that a subject with a non-winner's curse proposal

\footnotetext{
${ }^{23}$ The difference is not statistically significant according to the Wilcoxon signed-rank test, $n=15, p$-value $=0.733$ and one sample t-test p-value $=0.369$.

${ }^{24}$ Existing studies of group decision making greatly differ on this point, which crucially affects the incentives for communicating with others and for convincing others of one's opinion (Zhang and Casari, 2012). Cooper and Kagel (2005) randomly select one member's proposal as the group choice. Blinder and Morgan (2005) and Gillet et al. (2009) either implement a majority rule or give members no time limit to reach a unanimous decision. Kocher and Sutter (2007) is the most closely related paper with a veto power feature. In a gift-exchange game, Kocher and Sutter allowed groups of three up to 10 rounds to reach agreement. If there was no agreement in the $10^{\text {th }}$ round, each group member received only a show-up fee. Only one group failed to reach an agreement. They didn't analyze the effect of such veto power though. Kagel et al. (2010) studied the veto power in a committee where only one of the three committee members is a veto player.
} 
always vetoed group decisions for a winner's curse bid, in the group treatment, in the easy task only $1.5 \%$ of bids would have been winner's curse in the main part (and not 9.7\%). The corresponding percentages in the difficult task are $48.0 \%$ and $60.5 \%$, respectively. In other words, a rational use of veto power could have substantially reduced the fraction of winner's curse bids. Participants simply did not employ it as much as they could.

Another factor affecting bidding is risk preferences. For a risk neutral buyer the Nash Equilibrium (RNNE) strategy is to bid 60. A risk averse buyer, instead, may choose a "safe" bid of 38 while a risk seeking one may place a "naive" bid of 90. Subjects show considerable awareness of the risk characterizing the task when writing up reasons for their bid proposals and often interpret the task as choice over lotteries. For instance, a bid of 38 is called the "Safest Bet,” and a bid of 60 is described as “... a 1/5 chance of gaining 30 tokens and 1/5 chance of losing 3 tokens..conservative.” Another subject writes: “if we chose 90 then we can only lose 33 chips and can win 45 ..with 130 you can lose 73 or 40 and win 5 or 65.240 is just not worth it.” Here we investigate whether the shift in risk preference due to group decision making may explain the bid improvement from the Individual to the Group treatment. ${ }^{25}$ The question is empirical and refers to this specific setting. If there is a systematic tendency of individuals interacting in groups to take less risk than the same individuals deciding in isolation, then groups will lower their bids in the Acquiring a Company task. Without an independent task to measure shifts in risk preferences, one could erroneously attribute an improvement in performance of groups over individuals to superior group rationality instead of a shift in risk preferences. The previous literature on cautious shift or risky shift provides mixed results. ${ }^{26}$

Result 8: The shift in revealed risk preference generated by group decision-making cannot explain the better performance of groups over individuals in the Acquiring a Company task.

Each group made 15 lottery choices for a total of 675 group decisions (group lottery part). We measured agreement by comparing individual choices in lotteries and group lottery choices. In

\footnotetext{
${ }^{25}$ The observed levels of risk attitude cannot explain the winner's curse phenomenon in the Individual treatment. Approximately $10 \%$ of the participants showed risk seeking behaviour, and hence $90 \%$ of bids should be either 38 or 60 in the easy task (see Table A3). Instead, they were $47.5 \%$. This finding by itself is an important result for the winner's curse literature in general: the origin of the winner's curse when participants decide in isolation does not lie in the risk attitude of participants.

${ }^{26}$ See Zhang and Casari (2012) for a detailed literature review.
} 
$67.4 \%$ of the group decisions, there was unanimous agreement in the group. Overall, we found that group choices over lotteries were closer to the behavior of a risk neutral agent than individual choices and did not detect a systematic shift toward more risk averse behavior in group decision making. ${ }^{27}$

\section{Discussion and Conclusions}

Many bidders are naïve and often fall prey into the winner's curse, which is a widespread behavioral bias in the field and in the lab where people systematically incur losses when trying to acquire an item in a variety of settings. These settings include mineral right auctions, some eBay auctions, baseball's free agency market, IPOs pricing and corporate takeovers. Our aim is not to find the origin of naïve bidding or of the winner's curse but to study whether, and under what conditions, deciding in groups improves bidding and how this result is achieved.

In the simplified version of the Acquiring a Company task, we document the impact of four factors in group decision making under a unanimity rule. First, we report that individual opinions are combined into a group decision largely through a median-aggregation rule. When in disagreement, three out of four groups' choices in the easy task and two out of three in the difficult task are led by the opinion of the median member (Result 6). The Acquiring a Company task is an intellective task, where the dominant decision scheme is "truth wins," and groups are expected to perform at the level of the best individual in the group (Lorge and Solomon, 1955). We report that group performance falls short of the "truth wins" benchmark (Result 5). When in disagreement, controlling for risk attitude and some demographic characteristics - the best proposal in a group is no more likely to emerge than other proposals. Earlier papers compare group choices with simulations on individual choices in between-subject design (Cooper and Kagel, 2005, 2009). In addition to that, this study provides direct evidence by matching each group choice with the corresponding individual proposals of its group members. When two people do not get the correct solution, bringing a smart person into the group will not be enough, on average, to overturn the group decisions. The Acquiring a Company task is a demonstrable intellective task but it is as if subjects in small groups of three played it out as a judgmental task

\footnotetext{
${ }^{27}$ Table A3 in Appendix reports the detailed results. The fraction of risk neutral and risk seeking groups was lower than the fraction of risk neutral and risk seeking individuals (14.4\% vs. 13.64\%). The bulk of the choices reflected risk averse behavior. A two-sample Kolmogorov-Smirnov test did not show a significant difference though $(\mathrm{p}=0.349)$.
} 
before they learned to solve it. Such evidence unveils one reason why the winner's curse is so difficult to overcome. Even many of those who place an optimal bid don't seem to be aware of having correctly solved the task and are unable to overturn the group choice by effectively arguing that their proposal is the best. Furthermore, it also sheds light on a factor behind the lack of predictive power of the "truth-wins" model in these tasks. It isn't enough that a task be demonstrable intellective. For the truth-wins model to work, participants must experience a eureka moment for grasping the solution and then be able to unambiguously communicate this solution to others in the group, which was not the case either in the easy or in the difficult Acquiring a Company task in this study.

Our findings thus add nicely to the early psychology literature that postulates that a majority aggregation rule fits best for judgmental tasks that required consensus on a collective decision (Laughlin, 1999, Davis, 1992). The observed underperformance of groups in the difficult task is consistent with the findings in psychology and economics studies that when groups are facing tasks where individuals are likely to make intuitively appealing but incorrect judgments, groups tend to make poorer decisions than individuals (for instance, Smith et al. 1998; Hinsz et al. 2008, Charness et al., 2015) ${ }^{28}$ Moreover, relative to individuals, the same aggregation rule results in superior group performance in the easy task and inferior performance in the difficult task (Results 2, 3,6). This result supports the argument that the same decision process can lead to different group outcomes (Tindale et al. 2012). ${ }^{29}$

Second, in line with the experimental literature on group decision making, we find some evidence that groups learn faster than individuals (Results 2, 3 and 4). In our experiment, there is no significant learning by individuals who bid in an Acquiring a Company task (Result 1). We report substantial learning with experience by groups in the difficult task in terms of frequency of optimal bids and winner's curse bids (Result 3). We did not make headway in what exactly drives group learning. Feri et al. (2010) for instance argue that groups in coordination games are

\footnotetext{
${ }^{28}$ Smith et al. (1998) show that two person minorities can often persuade three person majorities to continue investing in a project that is falling. Hinsz et al. (2008) find groups are more likely to suffer from the base rate neglect problem than individuals.

29 Tindale et al. (2012) show that "social sharedness" - one of the basic group processes can lead to considerably different group outcomes, depending on whether shared knowledge interferes with the formal logic underlying the problem.
} 
more attracted by payoff-dominant choices than individuals deciding in isolation. This may be a behavioral force behind group learning also in this setting, where the main issue is instead the level of rationality. Nonetheless, repeated interaction emerges as a key factor to achieve a high group performance. One can only speculate that a longer interaction in the difficult task would have also improved group performance with respect to individual decision making.

Third, another likely factor in group decision making is herd behavior (Result 7). We provide indirect support on this point. While there was a group dynamic to converge to a middle ground as a compromise, some evidence suggests that there also existed another dynamic of herd behavior at play. Such behavior may take the explicit form of pressure from the majority or could be implicit, a self-retreat to conform to the majority. For instance, when there was an exante disagreement, the median was more likely to prevail in two-against-one situations than with three distinct opinions. Another way to detect the role of minority opinion is to look at the use of veto power. The veto power could have been usefully employed by a subject every time others in the group wanted to place a winner's curse bid because everyone generally prefers a sure gain of zero to an expected loss. Subjects exerted veto power substantially less often than optimal (Table 4).

Fourth, we can rule out that the superiority of groups over individuals in the easy version of the Acquiring a Company task is due to shifts in risk attitudes generated by group processes (Result 8). Very few experiments on group decision making controlled for this possible confounding factor. ${ }^{30}$

The above factors, but especially the median-aggregation rule, can provide a unified explanation for our experimental results. Groups of three members facing an intellective task can sometimes make better choices than individuals in isolation but in other situations show no improvement or a worsening in performance due to the transition from individual to group decision making. It depends on the combination of learning and of the process of aggregating individual proposals into a group choice. If groups follow the median opinion of their members, one would expect groups to perform better than individuals in easy tasks, because a large majority of individual subjects already avoids major mistakes such as winner's curse bids in the Acquiring a Company task. The same aggregation rule applied in a difficult task can lead to no

${ }^{30}$ An exception is Sheremeta and Zhang (2010). Following a similar group risk preference elicitation methods, they find groups of two are more risk averse than individuals yet risk-aversion does not have a significant effect on groups' bidding behavior in contests. 
improvement in the frequency of optimal bids by groups. If the task is very difficult, it could also make group decisions worse than individuals deciding in isolation. One would expect this result the larger is the share of individual subjects who fails to place near-optimal bids. Predictions following from this aggregation rule differ for tasks with internal vs. corner solutions. Groups are expected to fare better in tasks such as the one in the present experiment with an internal solution, given that - for any level of confusion or random error - it is harder for the median to coincide with a corner value of the action space.

The median-aggregation rule can also explain the experimental results of earlier experiments on group decision making. With auctions, groups did not seem to help much in overcoming the winner's curse or raising profits (Cox and Hayne, 2006, Sutter et al., 2009). Our findings do not contradict these results and may actually shed light on them. The Acquiring a Company task in the present study presents two major differences from those auctions: it is easier to solve and demonstrate the correct answer, and it does not involve competition with other subjects. In Cox and Hayne (2006) the experimental task was very difficult: "both individuals and groups are very subject to the winner's curse when they are inexperienced" (p.217). A similar issue applies to Sutter et al. (2009). Besides the level of difficulty, individual vs. group decision making in auction experiments may yield results different from ours because auctions generate issues of information aggregation and competition with other potential buyers that are ruled out by design under Acquiring a Company tasks with robot sellers. Further research may address the impact of competitive aspects in cognitively complex tasks in groupdecision making.

This paper suggests that groups perform well when a majority of individuals are able to overcome naïve bidding. Further research is needed to understand under what collective decision making rule, such as unanimity, majority, private or public message exchange, electronic or faceto-face communication, a minority can convince the group about the correct solution. Another open issue is how the above four factors play within groups of different sizes. For instance, one needs groups of three or larger to test a median-aggregation rule or herd behavior; or, larger groups may present a different speed of learning. 


\section{References}

Bajari, P., Hortacsu, A. 2003. The winner's curse, reserve prices, and endogenous entry: Empirical insights from eBay auctions. The RAND Journal of Economics 34(2) 329-355.

Ball, S. B., Bazerman, M. H., Carroll, J. S. 1991. An evaluation of learning in the bilateral winner's curse. Organizational Behavior and Human Decision Processes 48(1) 1-22.

Bereby-Meyer, Y., Grosskopf, B. 2008. Overcoming the winner's curse: An adaptive learning perspective. Journal of Behavioral Decision Making 21(1) 15-27.

Blinder, A. S., Morgan, J. 2005. Are two heads better than one? Monetary policy by committee. Journal of Money, Credit, and Banking 37(5) 769-811.

Brodbeck F. C., Kerschreiter R., Mojzisch A., Frey D, Schulz-Hardt S. 2007. Group decision making under conditions of distributed knowledge: The information asymmetries model. Academy of Management Journal, 32, 459-479.

Carroll, J. S., Delquie, P., Halpern, J. and Bazerman, M.H. 1990. Improving negotiators' cognitive processes. Working Paper, Massachusetts Institute of Technology, Cambridge, MA.

Charness, G., Cooper, D.J., Grossman, Z. 2015. Silence is golden: communication costs and team problem solving, Working Paper, University of California, Santa Barbara, CA.

Charness, G., Levin, D. 2009. The origin of the winner's curse: A laboratory study. American Economic Journal: Microeconomics 1(1) 207-236.

Charness, G., Karni, E., Levin, D. 2010. On the conjunction fallacy in probability judgment: New experimental evidence regarding Linda. Games and Economic Behavior 68(2) 551-556.

Charness, G., Sutter, M. 2012. Groups make better self-interested decisions. Journal of Economic Perspectives 26(3) 157-176.

Cooper, D. J., Kagel, J. H. 2005. Are two heads better than one? Team versus individual play in signaling games. American Economic Review 95(33) 477-509.

Cooper, D. J., Kagel, J.H. 2009. The role of context and team play in cross-game learning. Journal of the European Economic Association 7(5) 1101-1139.

Cooper, D. J., Sutter, M. 2011. Role Selection and Team Performance. IZA Discussion Paper No. 5892.

Cox, J. C., Hayne, S. C. 2006. Barking up the right tree: Are small groups rational agents? Experimental Economics 9(3) 209-222.

Davis, J. H. 1992. Some compelling intuitions about group consensus decisions, theoretical and empirical research, and interpersonal aggregation phenomena: Selected examples, 19501990. Organizational Behavior and Human Decision Processes 52(1) 3-38.

De Dreu, C.K.W., Nijstad, B.A., Van Knippenberg, D. 2008. Motivated information processing in group judgment and decision making. Personality and Social Psychology Review, 12, $22-$ 49.

Feri, F., Irlenbusch, B. and Sutter, M. 2010. Efficiency Gains from Team-Based CoordinationLarge-Scale Experimental Evidence. American Economic Review, 100, 4, 1892-1912.

Fischbacher, U. 2007. z-Tree-Zurich toolbox for readymade economic experiments. Experimental Economics 10(2) 171-178.

Gillet, J., Schram A., Sonnemans J. 2009. The tragedy of the commons revisited: The importance of group decision-making. Journal of Public Economics 93(5-6) 285-297.

Grosskopf, B., Bereby-Meyer, Y., Bazerman, M. 2007. On the robustness of the winner's curse phenomenon. Theory and Decision 63(4) 389-418. 
Hinsz, V. B., Tindale, R. S., Nagao, D. H. 2008. Accentuation of information processes and biases in group judgments integrating base-rate and case-specific information. Journal of Experimental Social Psychology, 44, 116-126.

Holt, C. A., Sherman, R. 1994. The loser's curse. American Economic Review 84 (3) 642-652.

Holt, C. A., Laury, S. K. 2002. Risk aversion and incentive effects. American Economic Review 92(5) 1644-1655.

Kagel, J. H., Sung, H., Winter, E. 2010. Veto power in committees: An experimental study. Experimental Economics 13(2) 167-188.

Kerr, N. L., MacCoun, R. J., Kramer, G. P. 1996. When are N heads better (or worse) than one? Biased judgments in individuals and groups, E. H. Witte \& J. H. Davis, eds. Understanding Group Behavior: Consensual Action By Small Groups 1 Erlbaum Associates, Mahwah, NJ, 105-136.

Kerr, N. L., Tindale, R. S. 2004. Group performance and decision-making. Annual Review of Psychology 55, 623-655.

Kocher, M. G., Sutter, M. 2005. The decision maker matters: Individual versus group behavior in experimental beauty-contest games. Economic Journal 115(500) 200-23.

Kocher, M. G., Sutter, M. 2007. Individual versus group behavior and the role of the decision making procedure in gift-exchange experiments. Empirica 31(1) 63-88.

Laughlin, P. R. 1980. Social combination processes of cooperative, problem-solving groups on verbal intellective tasks. M. Fishbein ed. Progress in Social Psychology 1 Erlbaum Associates, Hillsdale, NJ, 127-155.

Laughlin, P. R. 1999. Collective induction: Twelve postulates. Organizational Behavior and Human Decision Processes 80(1) 50-69.

Laughlin, P. R., Bonner, B. L., Miner, A. G. 2002. Groups perform better than the best individuals on Letters-to-Numbers problems. Organizational Behavior and Human Decision Processes 88(2) 605-620.

Laughlin, P. R., Ellis, A. L. 1986. Demonstrability and social combination processes on mathematical intellective tasks. Journal of Experimental Social Psychology 22(3) 177-189.

Laughlin, P. R., Hatch, E. C., Silver, J. S., Boh, L. 2006. Groups perform better than the best individuals on Letters-to-Numbers problems: Effects of group size. Journal of Personality and Social Psychology 90(4) 644-651.

Laughlin, P. R., VanderStoep, S. W., Hollingshead, A. B. 1991. Collective versus individual induction: recognition of truth, rejection of error, and collective information processing. Journal of Personality and Social Psychology 61(1) 50-67.

Laughlin, P. R., Zander, M. L., Knievel, E. M., Tan, T. K. 2003. Groups perform better than the best individuals on letters-to-numbers Problems: Informative equations and effective strategies. Journal of Personality and Social Psychology 85(4) 684-694.

Lorge, I., Solomon, H. 1955. Two models of group behavior in the solution of eureka-type problems. Psychometrika 20(2) 139-148.

Samuelson, W. 1984. Bargaining under asymmetric information. Econometrica 52(4) 995-1006.

Samuelson, W. F., Bazerman, M. H. 1985. The winner's curse in bilateral negotiations. V.L. Smith ed. Research in Experimental Economics 3 JAI Press, Greenwich, CT.

Sheremeta, R. M., Zhang, J. 2010. Can groups solve the problem of over-bidding in contests? Social Choice and Welfare 35(2) 175-197.

Selten, R., Abbink, K., Cox, R. 2005. Learning direction theory and the winner's curse. Experimental Economics 8 (1) 5-20. 
Smith, C. M., Tindale, R. S., Steiner, L. 1998. Investment decisions by individuals and groups in "sunk cost" situations: The potential impact of shared representations. Group Processes and Intergroup Relations 1, 175-189.

Sutter, M., Kocher, M., Strauss, S. 2009. Individuals and teams in auctions. Oxford Economic Papers 61(2) 380-394.

Tindale R.S., Smith C.M., Dykema-Engblade A., Kluwe K. 2012. Good and bad group performance: Same process-different outcomes. Group Processes and Intergroup Relations, 15 (5), pp. 603-618.

Tor, A., Bazerman, M.H. 2003. Focusing failures in competitive environments: Explaining decision errors in the Monty Hall game, the Acquiring a Company problem, and multiparty ultimatums. Journal of Behavioral Decision Making 16(5) 353-374.

Zhang, J., M. Casari 2012. How groups reach agreement in risky choices: An experiment. Economic Inquiry 50(2) 502-515. 


\section{Same Process, Different Outcomes: Group Performance in an Acquiring a Company Experiment}

Tables and Figures

Table 1: Buyer’s profits for selected bids -5-value version

\begin{tabular}{|c|c|c|c|c|c|c|}
\hline \multirow[b]{2}{*}{ Bid, $b$} & \multicolumn{5}{|c|}{$\begin{array}{c}\text { Profits } \\
\text { depending on the company value } s\end{array}$} & \multirow{2}{*}{$\begin{array}{c}\text { Expected } \\
\text { profits }\end{array}$} \\
\hline & $s=38$ & $s=60$ & $s=90$ & $s=130$ & $s=240$ & \\
\hline 38 (loss free) & 19 & 0 & 0 & 0 & 0 & 3.8 \\
\hline 60 (optimal) & -3 & 30 & 0 & 0 & 0 & 5.4 \\
\hline 90 (naïve) & -33 & 0 & 45 & 0 & 0 & 2.4 \\
\hline 130 & -73 & -40 & 5 & 65 & 0 & -8.6 \\
\hline 240 & -183 & -150 & -105 & -45 & 120 & -72.6 \\
\hline
\end{tabular}

Table 2: Experimental treatments

\begin{tabular}{llcc}
\hline \multicolumn{1}{c}{ Treatments } & $\begin{array}{c}\text { Number of } \\
\text { participants } \\
\text { (groups) }\end{array}$ & $\begin{array}{c}\text { Number of } \\
\text { sessions }\end{array}$ \\
\hline $\begin{array}{l}\text { 5-values } \\
\text { (easy task) }\end{array}$ & Individual treatment & 30 & 2 \\
\hline $\begin{array}{l}\text { 100-values } \\
\text { (difficult task) }\end{array}$ & Individual treatment & $60(20)$ & 4 \\
\hline
\end{tabular}


Table 3: Descriptive statistics

\begin{tabular}{|c|c|c|c|c|c|c|c|c|}
\hline & \multicolumn{4}{|c|}{ 5-value (easy task) } & \multicolumn{4}{|c|}{ 100-value (difficult task) } \\
\hline & \multicolumn{2}{|c|}{ Individual treatment } & \multicolumn{2}{|c|}{ Group treatment } & \multicolumn{2}{|c|}{ Individual treatment } & \multicolumn{2}{|c|}{ Group treatment } \\
\hline & control part & main part & control part & main part & control part & main part & control part & main part \\
\hline \multicolumn{9}{|l|}{ Percentage of Bids by type } \\
\hline $\begin{array}{l}\text { (Near) Optimal: bids that yield } \\
\text { highest expected profit }\end{array}$ & 35.6 & 37.5 & 30.6 & 50.5 & 15.6 & 22.7 & 22.2 & 13.0 \\
\hline $\begin{array}{l}\text { Suboptimal: bids that yield } \\
\text { positive expected profits }\end{array}$ & 44.4 & 44.2 & 51.1 & 39.8 & 14.4 & 11.7 & 13.3 & 26.5 \\
\hline $\begin{array}{l}\text { Winner's curse: bids that yield } \\
\text { negative expected profits }\end{array}$ & 20.2 & 18.3 & 18.3 & 9.8 & 70.0 & 65.7 & 64.4 & 60.5 \\
\hline Realized Profits (per period) & -1.65 & 0.40 & 1.21 & 2.13 & -2.83 & -0.75 & -0.50 & -2.4 \\
\hline Number of obs., Number of subjects & 180,30 & 600,30 & 360,60 & 400,60 & 90,15 & 300,15 & 180,30 & 200,30 \\
\hline
\end{tabular}

Note: In the 5-value treatment, optimal bid includes 60 and 61; winner's curse bids are in the ranges [58, 59], [74, 89] and [95, 360]. In the 100-value treatment, optimal bids are in the range [31, 53] and winner's curse bids are in the range [64, 360]. 
Table 4: Aggregation of individual proposals into a group choice

Group treatment, Main part

\begin{tabular}{|c|c|c|c|c|c|}
\hline \multirow{2}{*}{$\begin{array}{l}\text { Panel A: 5-value (easy task) } \\
\text { Group classification based } \\
\text { on individual proposals: }\end{array}$} & \multirow{2}{*}{$\begin{array}{l}\text { No. of } \\
\text { groups }\end{array}$} & \multirow{2}{*}{$\begin{array}{c}\text { No. of } \\
\text { proposals }\end{array}$} & \multicolumn{3}{|c|}{ No. of winner's cursed bids } \\
\hline & & & Actual & $\begin{array}{c}\text { Expected with } \\
\text { median aggregation }\end{array}$ & $\begin{array}{l}\text { Expected with truth wins } \\
\text { norm or veto power }\end{array}$ \\
\hline No winner's curse proposals & 304 & 912 & 3 & 0 & 0 \\
\hline There is only one winner's curse proposal & 72 & 216 & 54 & 0 & 0 \\
\hline There are two winner's curse proposals & 18 & 54 & 42 & 54 & 0 \\
\hline All winner's curse proposals & 6 & 18 & 18 & 18 & 18 \\
\hline Totals & 400 & 1,200 & 117 & 72 & 18 \\
\hline \multicolumn{2}{|l|}{ Frequency of winner's curse (out of 1200) } & $10.5 \%$ & $9.7 \%$ & $6.0 \%$ & $1.5 \%$ \\
\hline \multirow{2}{*}{$\begin{array}{l}\text { Panel B: 100-value (difficult task) } \\
\text { Group classification based } \\
\text { on individual proposals: }\end{array}$} & \multirow{2}{*}{$\begin{array}{l}\text { No. of } \\
\text { groups }\end{array}$} & \multirow{2}{*}{$\begin{array}{c}\text { No. of } \\
\text { proposals }\end{array}$} & \multicolumn{3}{|c|}{ No. of winner's cursed bids } \\
\hline & & & Actual & $\begin{array}{c}\text { Expected with } \\
\text { median aggregation }\end{array}$ & $\begin{array}{l}\text { Expected with truth wins } \\
\text { norm or veto power }\end{array}$ \\
\hline No winner's curse proposals & 57 & 171 & 0 & 0 & 0 \\
\hline There is only one winner's curse proposal & 23 & 69 & 21 & 0 & 0 \\
\hline There are two winner's curse proposals & 24 & 72 & 54 & 72 & 0 \\
\hline All winner's curse proposals & 96 & 288 & 288 & 288 & 288 \\
\hline Totals & 200 & 600 & 363 & 360 & 288 \\
\hline Frequency of winner's curse (out of 600) & & $59.8 \%$ & $60.5 \%$ & $60.0 \%$ & $48.0 \%$ \\
\hline
\end{tabular}


Table 5: Solving disagreement among individual proposals

Group treatment, Main part

\begin{tabular}{|c|c|c|c|c|c|c|c|c|}
\hline \multirow{5}{*}{$\begin{array}{l}\text { Dependent variable: } \\
1=\text { individual proposal } \\
\text { became group choice, } \\
0=\text { otherwise }\end{array}$} & \multicolumn{2}{|c|}{ 5-value } & \multicolumn{2}{|c|}{ 100-value } & \multicolumn{2}{|c|}{ 5-value } & \multicolumn{2}{|c|}{ 100-value } \\
\hline & All obs. & All obs. & All obs. & All obs. & Periods & Periods & Periods & Periods \\
\hline & Periods & Periods & Periods & Periods & $1-6$ & $7-20$ & $1-6$ & $7-20$ \\
\hline & $1-6$ & $7-20$ & $1-6$ & $7-20$ & & & & \\
\hline & (a) & (a) & (b) & (b) & (c) & (c) & (d) & (d) \\
\hline \multirow{2}{*}{$\begin{array}{l}\text { Proposal is median and } \\
\text { majority }\end{array}$} & $0.66^{* * *}$ & $0.69 * * *$ & $0.46 * * *$ & $0.67 * * *$ & & & & \\
\hline & $(0.115)$ & $(0.077)$ & $(0.160)$ & $(0.110)$ & & & & \\
\hline \multirow{2}{*}{$\begin{array}{l}\text { Proposal is median but } \\
\text { not majority }\end{array}$} & 0.03 & $0.40 * * *$ & $0.41 * * *$ & $0.35 * *$ & & & & \\
\hline & $(0.133)$ & $(0.069)$ & $(0.128)$ & $(0.162)$ & & & & \\
\hline \multirow{2}{*}{$\begin{array}{l}\text { Among group proposals, } \\
\text { it yields the highest } \\
\text { expected profit }\end{array}$} & 0.18 & -0.10 & -0.01 & -0.07 & & & & \\
\hline & $(0.123)$ & $(0.098)$ & $(0.177)$ & $(0.067)$ & & & & \\
\hline \multirow[t]{2}{*}{ Proposal is winner's curse } & & & & & $-0.34 * *$ & -0.09 & -0.11 & 0.14 \\
\hline & & & & & $(0.145)$ & $(0.182)$ & $(0.177)$ & $(0.111)$ \\
\hline \multirow[t]{2}{*}{ Proposal is optimal } & & & & & -0.19 & -0.05 & $-0.37 * * *$ & 0.17 \\
\hline & & & & & $(0.164)$ & $(0.103)$ & $(0.055)$ & $(0.164)$ \\
\hline \multirow{2}{*}{$\begin{array}{l}\text { Subject is risk averse } \\
\text { (switch point>13) }\end{array}$} & -0.05 & 0.04 & -0.03 & 0.02 & $-0.31 * *$ & -0.01 & 0.16 & 0.05 \\
\hline & $(0.102)$ & $(0.108)$ & $(0.120)$ & $(0.076)$ & $(0.132)$ & $(0.067)$ & $(0.150)$ & $(0.081)$ \\
\hline \multirow{2}{*}{$\begin{array}{l}\text { Subject is risk seeking } \\
\text { (switch point }<8 \text { ) }\end{array}$} & $-0.31 * * *$ & -0.08 & 0.22 & $\wedge$ & 0.01 & -0.09 & $0.46^{* *}$ & $\wedge$ \\
\hline & $(0.079)$ & $(0.150)$ & $(0.198)$ & & $(0.128)$ & $(0.194)$ & $(0.182)$ & \\
\hline \multirow[t]{2}{*}{ High confidence proposal } & -0.10 & 0.11 & 0.05 & -0.06 & 0.04 & 0.06 & 0.16 & -0.01 \\
\hline & $(0.113)$ & $(0.078)$ & $(0.081)$ & $(0.105)$ & $(0.201)$ & $(0.099)$ & $(0.114)$ & $(0.118)$ \\
\hline \multirow{2}{*}{$\begin{array}{l}\text { Economics and Business } \\
\text { major }\end{array}$} & -0.05 & -0.08 & 0.13 & 0.12 & -0.08 & -0.16 & 0.14 & $0.21 *$ \\
\hline & $(0.068)$ & $(0.114)$ & $(0.154)$ & $(0.115)$ & $(0.115)$ & $(0.113)$ & $(0.158)$ & $(0.116)$ \\
\hline \multirow[t]{2}{*}{ Male } & 0.14 & -0.01 & 0.12 & $0.13^{* *}$ & 0.03 & -0.14 & 0.15 & $0.09 *$ \\
\hline & $(0.094)$ & $(0.067)$ & $(0.107)$ & $(0.052)$ & $(0.126)$ & $(0.109)$ & $(0.111)$ & $(0.054)$ \\
\hline $\begin{array}{l}\text { Number of obs., Number } \\
\text { of subjects }\end{array}$ & 230,59 & 386, 45 & 123,30 & 243,30 & 98,38 & 172, 36 & 123, 30 & 222,21 \\
\hline Pseudo R-squared & 0.388 & 0.349 & 0.198 & 0.321 & 0.110 & 0.052 & 0.098 & 0.090 \\
\hline Log likelihood & -96.57 & -172.8 & -64.31 & -107.2 & -60.26 & -112.9 & -72.36 & -129.2 \\
\hline
\end{tabular}

Notes: Marginal effects from probit regression with robust standard errors (clusters on groups). Significance levels $* * * \mathrm{p}<0.01,{ }^{* *} \mathrm{p}<0.05$, ${ }^{*} \mathrm{p}<0.1$. Specifications (a), (b) include all individual proposals unless all identical within the group in a given period (616 obs. in 5-value; 366 obs. in 100-value) Specifications (c) and (d) include all the observations when there is a disagreement in the proposal stage with at least one proposal is a winners' cursed bid (270 obs. in 5-value; 345 in 100-value) and when the final group decision is winner's cursed bid even though none of the proposals are winner's cursed bids (3 obs. in 5-value; 0 obs. in 100-value). $\wedge$ r_seeking dropped due to collinearity. Observations affected by limited liability issues are excluded. Period dummies are not reported in the interest of space. 
Figure 1: Individual and group performance over time

\section{5-value (easy task)}

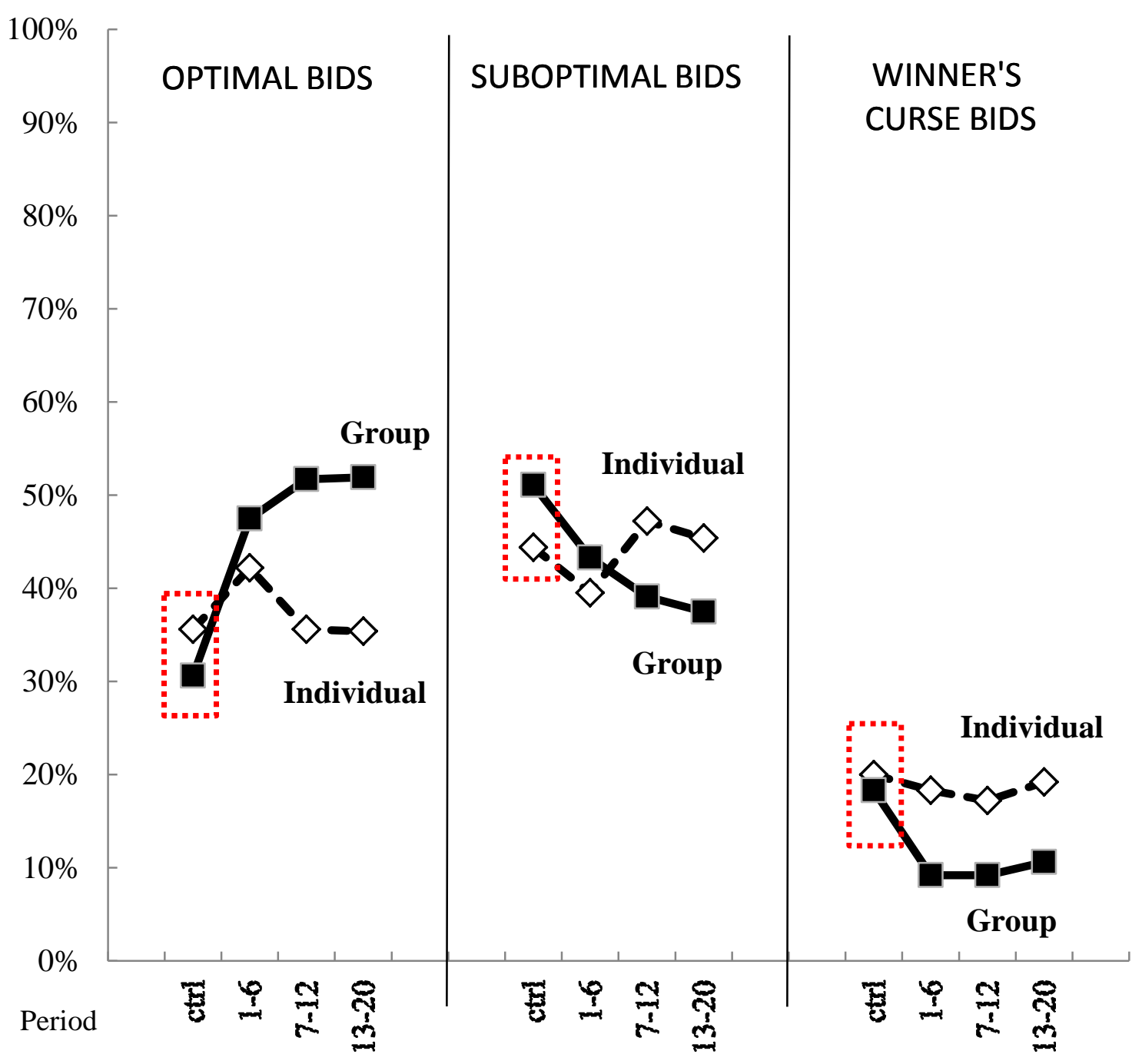




\section{0-value (difficult task)}

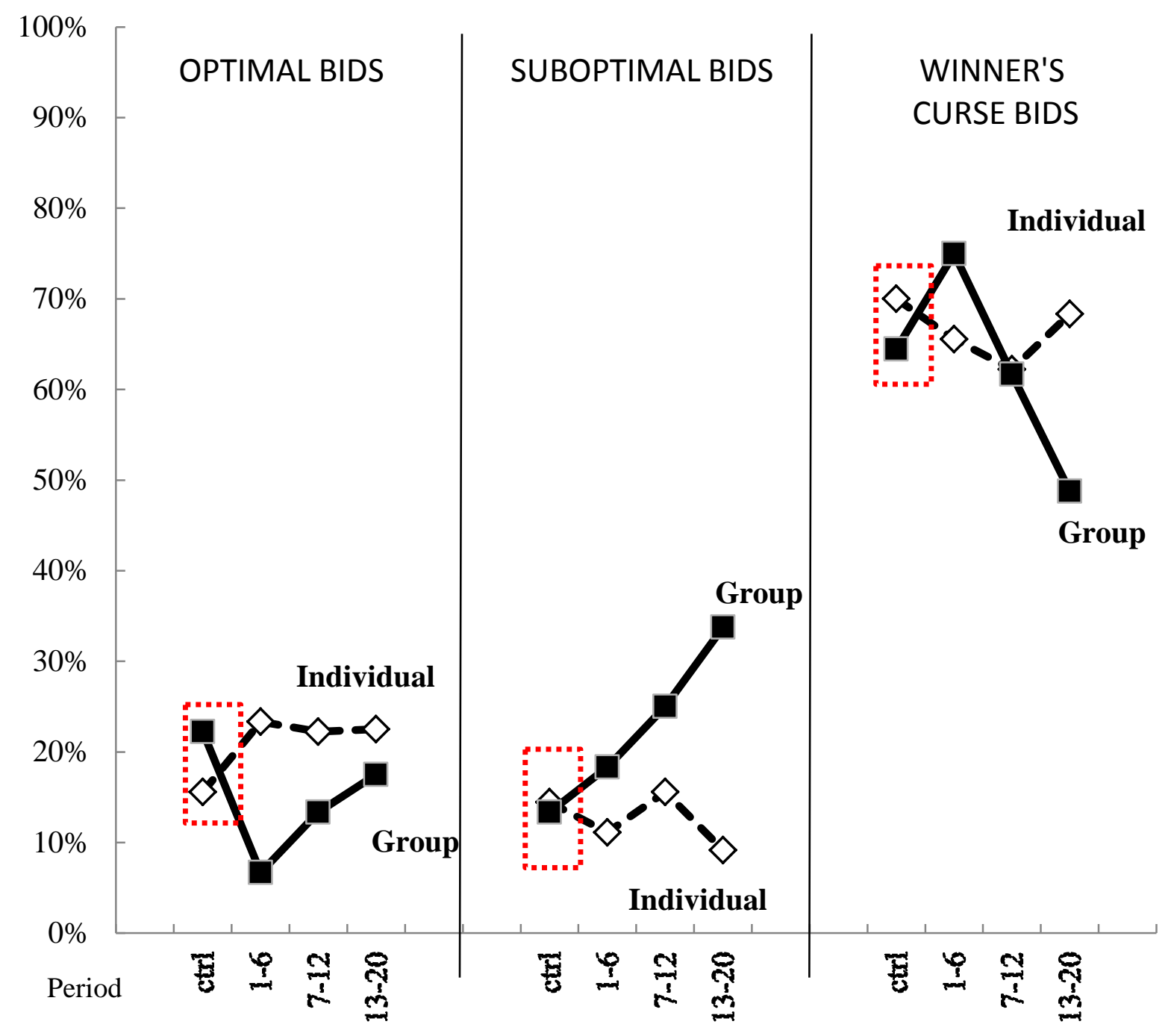

Notes: This figure displays the fractions of optimal bids (left panel), winner's curse bids (middle panel) and dispersed bids (right panel) average across four segments of time. The first data point in each panel is the average of 6 periods in the control part. The next three points report the average fraction of bids in the three segments in the main part (periods 1-6, periods 7-12, and periods 13-20, respectively). 
Figure 2a: Group choices over time

\section{5-values (easy task)}

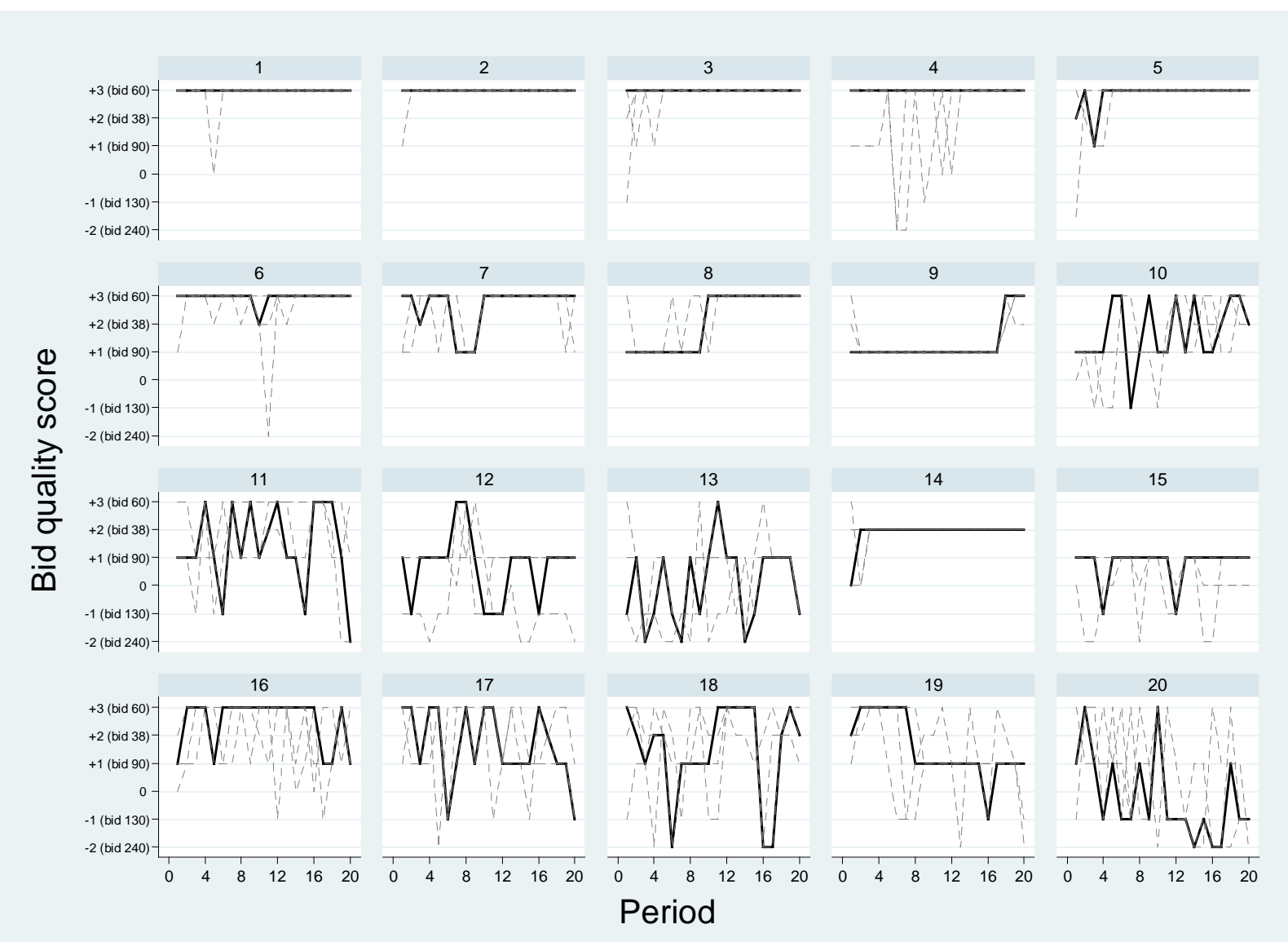

Notes: This figure shows for each group the evolution of the final group bid (solid line) and the individual bid proposals (dashed lines). Each panel represents a single group $(\mathrm{N}=20)$. Bids are mapped into a quality score ranging from -2 (worst bids) to +3 (best bids). The score for any other bid not present on the vertical axis is the average value of the two closest bids in terms of profits: $2.5,1.5,0$, -1.5. Bids above 240 are coded with -3 . Comparing the group performance between periods $1-3$ and periods 17-19 based on the average quality score of the final bid with the average score of the proposals as a tie-breaking rule, we report that 14 groups exhibited an improvement (panels 2-15), 1 group stayed constant (panel 1) and 5 groups got worse (panels 16-20). 
Figure 2b: Group choices over time

\section{0-values (difficult task)}

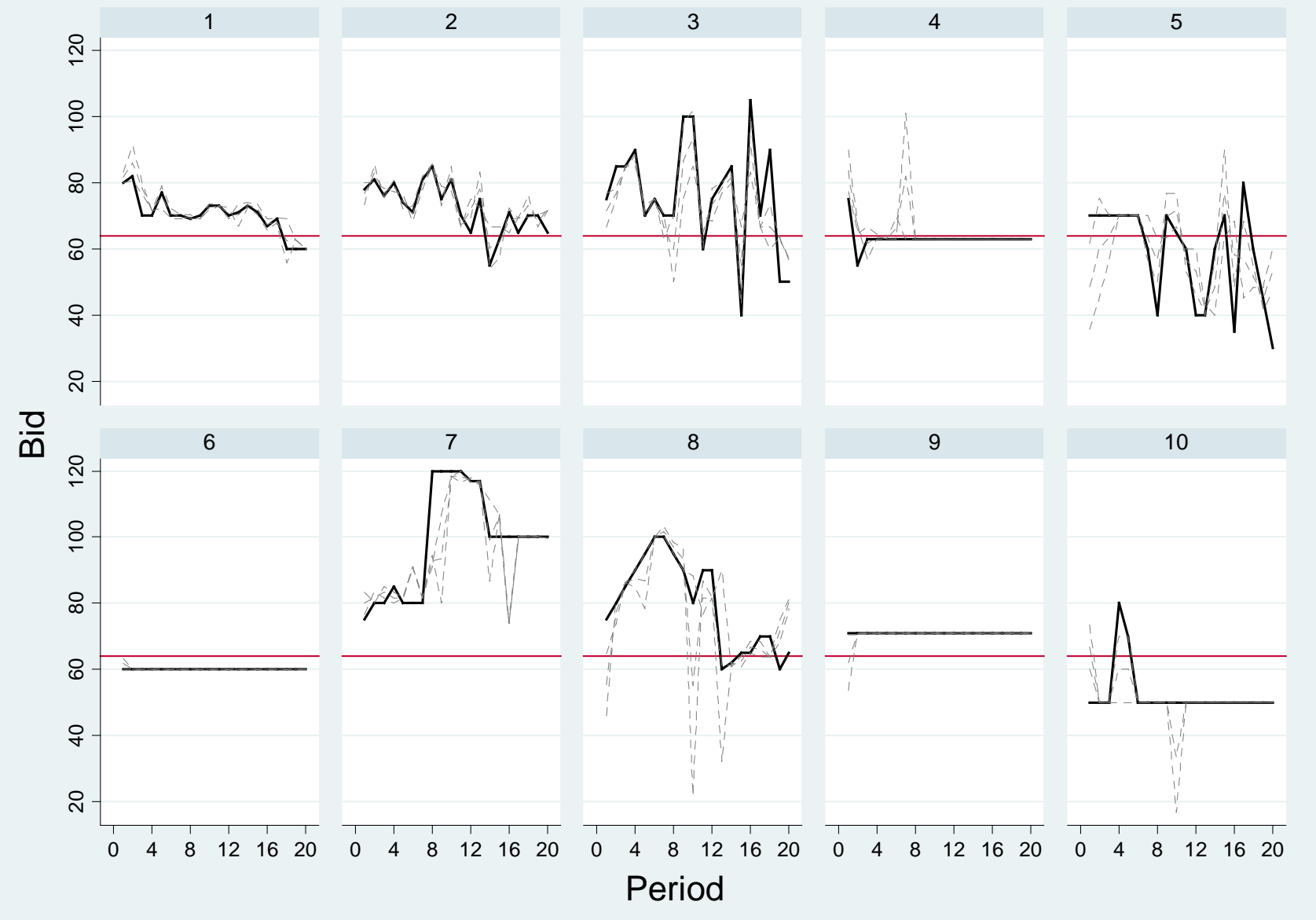

Notes: This figure shows for each group the evolution of the final group bid (solid line) and the individual bid proposals (dashed lines). Each panel represents a single group ( $\mathrm{N}=10)$. Bids above 64 (the red horizontal line) is winner's curse bid. Comparing the group performance between periods 1-3 and periods 17-19 based on the average expected payoff of the final bid, we report that 6 groups exhibited an improvement (panels 1-5 and 8), 3 groups stayed constant (panels 6, 9, 10) and 1 group got worse (panel 7). 


\section{APPENDIX}

Table A1: Experimental studies of the acquiring a company game

\begin{tabular}{|c|c|c|c|c|c|c|c|}
\hline \multirow[b]{2}{*}{ Paper } & \multirow[b]{2}{*}{ Design } & \multicolumn{3}{|c|}{ Seller value } & \multirow[b]{2}{*}{$\begin{array}{c}\text { Value } \\
\text { multiplier is } \\
50 \% ?\end{array}$} & \multirow[b]{2}{*}{$\begin{array}{l}\text { Equilibrium } \\
\text { bid } \\
\text { in choice set }\end{array}$} & \multirow[b]{2}{*}{ No. repetitions } \\
\hline & & $\begin{array}{l}\text { Lower } \\
\text { bound }\end{array}$ & $\begin{array}{l}\text { Upper } \\
\text { bound }\end{array}$ & $\begin{array}{l}\text { Continuo } \\
\text { us set? }\end{array}$ & & & \\
\hline \multirow{2}{*}{$\begin{array}{l}\text { Casari et al. } \\
\text { (2015: this study) }\end{array}$} & 5 values & 38 & 240 & & $\mathbf{Y}$ & $11 \%$ & 26 \\
\hline & 100 values & 21 & 120 & & $\mathbf{Y}$ & $22 \%$ & 26 \\
\hline \multirow{3}{*}{$\begin{array}{l}\text { Ball, Bazerman, } \\
\text { Carroll (1991) }\end{array}$} & Baseline & 0 & 100 & $\mathrm{Y}$ & $\mathrm{Y}$ & $0 \%$ & 20 \\
\hline & Role Reversal & 0 & 100 & $\mathrm{Y}$ & $\mathrm{Y}$ & $0 \%$ & 20 \\
\hline & Extended Trial & 0 & 100 & $\mathrm{Y}$ & $\mathrm{Y}$ & $0 \%$ & 20 \\
\hline \multirow{5}{*}{$\begin{array}{l}\text { Charness and } \\
\text { Levin (2009) }\end{array}$} & 100 values & 0 & 99 & & $\mathrm{Y}$ & $0 \%$ & 60 \\
\hline & 100 values & 20 & 119 & & $\mathrm{Y}$ & $20 \%$ & 60 \\
\hline & 2 values & 0 & 99 & & $\mathrm{Y}$ & $0 \%$ & 60 \\
\hline & 2 values & 20 & 119 & & $\mathrm{Y}$ & $0 \%$ & 60 \\
\hline & 4 values & 0 & 99 & & $\mathrm{Y}$ & $0 \%$ & 60 \\
\hline $\begin{array}{l}\text { Cooper and Sutter } \\
\text { (2011) }\end{array}$ & 3 values & 90 & 1200 & & $\mathrm{Y}$ & $5 \%$ & 40 \\
\hline \multirow{3}{*}{$\begin{array}{l}\text { Holt and Sherman } \\
\text { (1994) }\end{array}$} & Winner's Curse & 1.5 & 6 & $\mathrm{Y}$ & $\mathrm{Y}$ & $33 \%$ & 30 \\
\hline & No Curse & 1 & 3 & $\mathrm{Y}$ & $\mathrm{Y}$ & $50 \%$ & 30 \\
\hline & Loser's Curse & 0.5 & 1 & $\mathrm{Y}$ & $\mathrm{Y}$ & $100 \%$ & 30 \\
\hline \multirow{3}{*}{$\begin{array}{l}\text { Selton, Abbink, } \\
\text { and Cox (2005) }\end{array}$} & Lower bound of 1 & 1 & 99 & $\mathrm{Y}$ & & $0-1 \%$ & 100 \\
\hline & Lower bound of 11 & 11 & 99 & $\mathrm{Y}$ & & $11-13 \%$ & 100 \\
\hline & Lower bound of 21 & 21 & 99 & $\mathrm{Y}$ & & $26-27 \%$ & 100 \\
\hline \multirow{5}{*}{$\begin{array}{l}\text { Bereby-Meyer and } \\
\text { Grosskopf (2008) }\end{array}$} & Control & 0 & 100 & $\mathrm{Y}$ & $\mathrm{Y}$ & $0 \%$ & 100 \\
\hline & Yes-No Decision 1st & 0 & 100 & $\mathrm{Y}$ & $\mathrm{Y}$ & $0 \%$ & 100 \\
\hline & $\begin{array}{l}\text { Average Full } \\
\text { Feedback }\end{array}$ & 0 & 100 & $\mathrm{Y}$ & $\mathrm{Y}$ & $0 \%$ & 100 \\
\hline & Average Only & 0 & 100 & $\mathrm{Y}$ & $\mathrm{Y}$ & $0 \%$ & 100 \\
\hline & Gamble & 0 & 100 & & $\mathrm{Y}$ & $0 \%$ & 100 \\
\hline \multirow{6}{*}{$\begin{array}{l}\text { Grosskopf, } \\
\text { Bereby-Meyer, } \\
\text { Bazerman (2007) }\end{array}$} & Control & 0 & 100 & $\mathrm{Y}$ & $\mathrm{Y}$ & $0 \%$ & 100, 5 parts \\
\hline & Varying $k$ & 0 & 100 & $\mathrm{Y}$ & & $0 \%, 100 \%$ & 100, 5 parts \\
\hline & Sym-Asym & 0 & 100 & $\mathrm{Y}$ & $\mathrm{Y}$ & $0 \%, 51 \%$ & 100,5 parts \\
\hline & Sym-Asym Compar. & 0 & 100 & $\mathrm{Y}$ & $\mathrm{Y}$ & $0 \%, 51 \%$ & 100, 5 parts \\
\hline & Exper 2: Control & 0 & 100 & $\mathrm{Y}$ & $\mathrm{Y}$ & $0 \%, 51 \%$ & $80+20$ switch \\
\hline & Exper 2: Foregone & 0 & 100 & $\mathrm{Y}$ & $\mathrm{Y}$ & $0 \%, 51 \%$ & $80+20$ switch \\
\hline \multirow{5}{*}{$\begin{array}{l}\text { Carroll, Delquie, } \\
\text { Halpern, } \\
\text { Bazerman (1990) }\end{array}$} & Control & 0 & 100 & $\mathrm{Y}$ & $\mathrm{Y}$ & $0 \%$ & 1 \\
\hline & High Motives & 0 & 100 & $\mathrm{Y}$ & $\mathrm{Y}$ & $0 \%$ & 1 \\
\hline & Training (x4) & 0 & 100 & $\mathrm{Y}$ & $\mathrm{Y}$ & $0 \%$ & 1 \\
\hline & Exper. Mngrs & 0 & 100 & $\mathrm{Y}$ & $\mathrm{Y}$ & $0 \%$ & 1 \\
\hline & Exper. Bankers & 0 & 100 & $\mathrm{Y}$ & $\mathrm{Y}$ & $0 \%$ & 1 \\
\hline $\begin{array}{l}\text { Tor and Bazerman } \\
(2003)\end{array}$ & & 0 & 100 & $\mathrm{Y}$ & $\mathrm{Y}$ & $0 \%$ & 1 \\
\hline
\end{tabular}

Notes to Table A1: The subjects were undergraduate students except in the following studies. Ball, Bazerman, Carroll (1991) used 1st year Master students; Bereby-Meyer and Grosskopf (2008) used Boston area people, varied in education and background; Grosskopf, Bereby-Meyer, Bazerman (2007) used Boston area people, age 18 to 60; Carroll, Delquie, Halpern, Bazerman (1990) used 1st year Master's students in OBHR class, 2nd year Master's students in advanced Marketing class, Managers in a weeklong seminar and Master's graduates in investment banking; Tor and Bazerman (2003) used both graduate and undergraduate students. Other papers used standard undergraduate students as subjects. 
Table A2: Descriptive statistics on simulated median bids

\begin{tabular}{|c|c|c|c|c|c|c|c|c|}
\hline & \multicolumn{4}{|c|}{ 5-value (easy task) } & \multicolumn{4}{|c|}{ 100-value (difficult task) } \\
\hline & \multicolumn{2}{|c|}{ Individual treatment } & \multicolumn{2}{|c|}{ Group treatment } & \multicolumn{2}{|c|}{ Individual treatment } & \multicolumn{2}{|c|}{ Group treatment } \\
\hline & control part & main part & control part & main part & control part & main part & control part & main part \\
\hline $\begin{array}{l}\text { Simulated median bid distribution } \\
\text { (percentages) }\end{array}$ & & & & & & & & \\
\hline $\begin{array}{c}\text { (Near) Optimal: bids that yield } \\
\text { highest expected profit }\end{array}$ & 33.97 & 44.40 & 36.58 & 60.13 & 8.16 & 16.76 & 15.47 & 7.74 \\
\hline $\begin{array}{l}\text { Suboptimal: bids that yield } \\
\text { positive expected profits }\end{array}$ & 53.99 & 46.24 & 53.48 & 36.41 & 14.13 & 11.33 & 13.66 & 28.54 \\
\hline $\begin{array}{l}\text { Winner's curse: bids that yield } \\
\text { negative expected profits }\end{array}$ & 12.04 & 9.36 & 9.94 & 3.46 & 77.71 & 71.92 & 70.87 & 63.72 \\
\hline Number of simulated observations & 36000 & 120000 & 36000 & 120000 & 36000 & 120000 & 36000 & 120000 \\
\hline
\end{tabular}

Notes: In the group treatment, Main part, the simulations were run on the individual proposed bids without regard for the experimental group membership. 
Table A3: Lottery choice task

\begin{tabular}{|c|c|c|c|c|c|c|c|}
\hline & $\begin{array}{c}\text { Option } \\
A\end{array}$ & & $\begin{array}{c}\text { Option } \\
B \\
\end{array}$ & & Risk Preference & $\begin{array}{c}\text { Individual } \\
\text { Choices }\end{array}$ & $\begin{array}{c}\text { Group } \\
\text { Choices }\end{array}$ \\
\hline \multirow[t]{2}{*}{$\begin{array}{c}\text { Decision } \\
\text { node }\end{array}$} & \multirow[t]{2}{*}{ Payoffs } & \multirow[t]{2}{*}{ Payoffs } & \multirow{2}{*}{$\begin{array}{l}\text { Probability } \\
\text { of getting } \\
150 \text { tokens }\end{array}$} & \multirow{2}{*}{$\begin{array}{l}\text { Expected } \\
\text { payoff of } \\
\text { option B }\end{array}$} & \multirow{2}{*}{$\begin{array}{c}\text { Range of CRRA If } \\
\text { switch from A to B at } \\
\text { the following decision } \\
\text { node }\end{array}$} & $\begin{array}{l}\text { Frequency } \\
\text { of choices } \\
\text { for B }\end{array}$ & $\begin{array}{l}\text { Frequency } \\
\text { of choices } \\
\text { for B }\end{array}$ \\
\hline & & & & & & $(\%)$ & $(\%)$ \\
\hline 1 & 50 & 150 or 0 & 0 & 0 & $\mathrm{r}<-1.73$ & 0.00 & 0.00 \\
\hline 2 & 50 & 150 or 0 & 0.05 & 7.5 & $-1.73<\mathrm{r}<-1.1$ & 0.00 & 0.00 \\
\hline 3 & 50 & 150 or 0 & 0.1 & 15 & $-1.1<\mathrm{r}<-0.73$ & 0.00 & 0.00 \\
\hline 4 & 50 & 150 or 0 & 0.15 & 22.5 & $-0.73<\mathrm{r}<-0.47$ & 0.00 & 0.00 \\
\hline 5 & 50 & 150 or 0 & 0.2 & 30 & $-0.47<\mathrm{r}<-0.27$ & 1.69 & 0.00 \\
\hline 6 & 50 & 150 or 0 & 0.25 & 37.5 & $-0.27<\mathrm{r}<-0.1$ & 3.39 & 0.00 \\
\hline 7 & 50 & 150 or 0 & 0.3 & 45 & $-0.1<\mathrm{r}<0.04$ & 5.08 & 0.76 \\
\hline 8 & 50 & 150 or 0 & 0.35 & 52.5 & $0.04<r<0.16$ & 14.41 & 13.64 \\
\hline 9 & 50 & 150 or 0 & 0.4 & 60 & $0.16<\mathrm{r}<0.27$ & 22.03 & 16.67 \\
\hline 10 & 50 & 150 or 0 & 0.45 & 67.5 & $0.27<\mathrm{r}<0.36$ & 29.66 & 36.36 \\
\hline 11 & 50 & 150 or 0 & 0.5 & 75 & $0.36<\mathrm{r}<0.45$ & 62.71 & 69.70 \\
\hline 12 & 50 & 150 or 0 & 0.55 & 82.5 & $0.45<\mathrm{r}<0.53$ & 72.03 & 83.33 \\
\hline 13 & 50 & 150 or 0 & 0.6 & 90 & $0.53<\mathrm{r}<0.6$ & 82.20 & 88.64 \\
\hline 14 & 50 & 150 or 0 & 0.65 & 97.5 & $0.6<\mathrm{r}<0.66$ & 90.68 & 95.45 \\
\hline 15 & 50 & 150 or 0 & 0.7 & 105 & $0.66<\mathrm{r}$ & 94.92 & 97.73 \\
\hline \multicolumn{6}{|c|}{ Percentage of monotonic decision makers } & 87.41 & 97.81 \\
\hline
\end{tabular}

Notes: Everyone should choose option A in decision 1. Risk neutral subjects would switch to option B in decision 8 (italics). A switch in later decisions reveals risk aversion and a switch in earlier decisions reveals risk seeking behavior. Number of observations: 118 in individual choices and 132 in group choices (non-monotonic choices are excluded). 
Table A4: Summary of descriptive statistics

\begin{tabular}{|r|c|c|c|c|c|c|}
\hline & \multicolumn{3}{|c|}{ 5-value (easy task) } & \multicolumn{3}{c|}{100 -value (difficult task) } \\
\hline Percentage of Bids By Type & $\begin{array}{c}\text { Individual } \\
\text { Bid }\end{array}$ & $\begin{array}{c}\text { Group } \\
\text { Bid }\end{array}$ & $\begin{array}{c}\text { Individual } \\
\text { Proposal }\end{array}$ & $\begin{array}{c}\text { Individual } \\
\text { Bid }\end{array}$ & $\begin{array}{c}\text { Group } \\
\text { Bid }\end{array}$ & $\begin{array}{c}\text { Individual } \\
\text { Proposal }\end{array}$ \\
\hline (Near) Optimal & & & & & & \\
\hline control & $35.6 \%$ & $30.6 \%$ & $30.6 \%$ & $15.6 \%$ & $22.2 \%$ & $22.2 \%$ \\
main 1-6 & $42.2 \%$ & $47.5 \%$ & $43.3 \%$ & $23.3 \%$ & $6.7 \%$ & $11.1 \%$ \\
main 7-12 & $35.6 \%$ & $51.7 \%$ & $48.6 \%$ & $22.2 \%$ & $13.3 \%$ & $12.8 \%$ \\
\hline Winner's Curse & $35.4 \%$ & $51.9 \%$ & $52.3 \%$ & $22.5 \%$ & $17.5 \%$ & $19.6 \%$ \\
\hline control & & & & & & \\
main 1-6 & $18.3 \%$ & $9.2 \%$ & $11.4 \%$ & $65.6 \%$ & $75.0 \%$ & $72.8 \%$ \\
main 13-12 & $17.2 \%$ & $9.2 \%$ & $10.6 \%$ & $62.2 \%$ & $61.7 \%$ & $60.6 \%$ \\
\hline
\end{tabular}

Table A5: Within-treatment comparison: Wilcoxon signed-rank test, two-sided p-values

\begin{tabular}{|c|c|c|c|c|c|}
\hline \multicolumn{3}{|c|}{ 5-value (easy task) } & \multicolumn{3}{|c|}{ 100-value (difficult task) } \\
\hline \multicolumn{6}{|c|}{ compare control vs. main (1-6) } \\
\hline & (near) optimal & winner's curse & & (near) optimal & winner's curse \\
\hline $\begin{array}{l}\text { individual bid } \\
\qquad \mathrm{n}=30\end{array}$ & 0.1119 & 0.4453 & $\begin{array}{l}\text { individual bid } \\
\qquad \mathrm{n}=15\end{array}$ & 0.0087 & 0.2245 \\
\hline $\begin{array}{c}\text { group bid } \\
n=20\end{array}$ & 0.108 & 0.0346 & $\begin{array}{c}\text { group bid } \\
n=10\end{array}$ & 0.0395 & 0.4443 \\
\hline \multicolumn{6}{|c|}{ compare main (1-6) vs. main (13-20) } \\
\hline & (near) optimal & winner's curse & & (near) optimal & winner's curse \\
\hline $\begin{array}{l}\text { individual bid } \\
\qquad \mathrm{n}=30\end{array}$ & 0.2121 & 1.000 & $\begin{array}{l}\text { individual bid } \\
\qquad \mathrm{n}=15\end{array}$ & 0.6474 & 0.8414 \\
\hline $\begin{array}{c}\text { group bid } \\
n=20\end{array}$ & 0.3761 & 0.9323 & $\begin{array}{l}\text { group bid } \\
n=10\end{array}$ & 0.0842 & 0.0107 \\
\hline \multicolumn{6}{|c|}{ compare control (1-6) vs. main (13-20) } \\
\hline & (near) optimal & winner's curse & & (near) optimal & winner's curse \\
\hline $\begin{array}{c}\text { individual bid } \\
n=30\end{array}$ & 0.9917 & 0.3392 & $\begin{array}{c}\text { individual bid } \\
n=15\end{array}$ & 0.2335 & 0.4545 \\
\hline $\begin{array}{c}\text { group bid } \\
n=20\end{array}$ & 0.0380 & 0.0261 & $\begin{array}{c}\text { group bid } \\
n=10\end{array}$ & 0.2591 & 0.2023 \\
\hline
\end{tabular}


Table A6: Fisher exact tests comparing the percentages of improved and worsen groups across treatments

\begin{tabular}{|c|c|c|c|c|c|c|}
\hline & \multicolumn{3}{|c|}{ 5-value } & \multirow[b]{2}{*}{ Improved } & \multirow[b]{2}{*}{ Worsen+ Constant } & \multirow[b]{2}{*}{ Total } \\
\hline & Improved & Worsen + Constant & Total & & & \\
\hline Individual Treatment & 12 & 18 & 30 & 7 & 8 & 15 \\
\hline Group Treatment & 14 & 6 & 20 & 6 & 4 & 10 \\
\hline Fisher Exact Test (two-sided) & \multicolumn{3}{|c|}{$p=0.048$} & \multicolumn{3}{|c|}{$p=0.668$} \\
\hline
\end{tabular}

Table A7: Between treatment comparison: Robust rank order tests, one-tailed asymptotic p-value

\begin{tabular}{|c|c|c|c|c|}
\hline \multirow{2}{*}{$\begin{array}{l}\text { Changes from } \\
\text { control part to main part }\end{array}$} & \multicolumn{2}{|c|}{ 5-value } & \multicolumn{2}{|c|}{ 100-value } \\
\hline & $\begin{array}{c}\text { (Near) } \\
\text { Optimal }\end{array}$ & $\begin{array}{c}\text { Winner's } \\
\text { Curse }\end{array}$ & $\begin{array}{c}\text { (Near) } \\
\text { Optimal }\end{array}$ & $\begin{array}{c}\text { Winner's } \\
\text { Curse }\end{array}$ \\
\hline Individual Treatment & 1.9 & -1.9 & 7.1 & -4.3 \\
\hline Group Treatment & 19.9 & -8.5 & -9.2 & -3.9 \\
\hline Robust rank order tests & $p=0.057$ & $p=0.057$ & $p=0.006$ & $p=0.244$ \\
\hline
\end{tabular}

